\title{
Acquisition and extinction of facilitation in the C57BL/6J mouse
}

\author{
LEAH ANN FETSKO, HILARY E. STEBBINS, KATHLEEN KELLY GALLAGHER, \\ and RUTH M. COLWILL \\ Brown University, Providence, Rhode Island
}

\begin{abstract}
Acquisition, extinction, and transfer of facilitation were explored in a series of experiments with C57BL/6J mice. With a procedure in which an auditory target was followed by food only in the presence of a visual facilitator, Experiments 1-4 showed that the facilitator promoted magazine entries to the auditory target. This enhancement effect was eliminated by training the facilitator as a conditioned inhibitor (Experiments 1 and 3B). Enhancement was also reduced by nonreinforced presentations of the facilitator in a discrimination procedure (Experiment 1) and by simple nonreinforcement of the facilitator (Experiments 2, 3A, and 4). In contrast to the results obtained with a facilitator, simple nonreinforcement of an inhibitor, a visual cue that had signaled when an auditory target would not be reinforced, did not reduce its ability to modulate responding to that target (Experiment 4). However, both the facilitator and the inhibitor were found to transfer their modulatory effects to other targets (Experiment 4). Finally, mice demonstrated no evidence of differential responding on a biconditional discrimination procedure in which one auditory target (A1) was reinforced in the presence of one visual stimulus (L1) but not in the presence of another (L2), and a different auditory target (A2) was reinforced in L2 but not in L1 (Experiment 5). The implications of these results for analysis of the function of a facilitator are discussed.
\end{abstract}

It is now well established that conditioned responding to a simple Pavlovian conditioned stimulus (CS) can be modulated by another cue. For instance, it has long been known that responding can be inhibited by a cue that signals when a CS will not be reinforced (Pavlov, 1927). More recently, it has been demonstrated that responding can be augmented by a cue that signals when a CS will be reinforced. This type of modulation was first reported for rats (Ross \& Holland, 1981) and has since been observed in rabbits (Brandon \& Wagner, 1991) and in pigeons (Rescorla, 1985). For example, Holland and his colleagues (Holland, 1983; Ross, 1983; Ross \& Holland, 1981) exposed rats to repeated presentations of a 5-sec tone CS that was followed by a food unconditioned stimulus (US) only when the tone was preceded by a 5 -sec light cue. Using this feature-positive procedure, they found that responding to the tone was considerably higher on the trials when it was preceded by the light. Rescorla (1985) has shown a parallel facilitating effect in pigeons. If a keylight was followed by a food US only when a diffuse auditory or visual stimulus preceded its presentation, pecking to the keylight occurred primarily on trials with the diffuse stimulus.

Evidence that this facilitation effect involves a modulatory process has come largely from an examination of the

This research was supported by National Institute on Drug Abuse Grant DA014202. We thank Robert Rescorla, Shepard Siegel, and two anonymous reviewers for their helpful comments. Correspondence concerning this article should be addressed to R. M. Colwill, Department of Psychology, Brown University, Box 1853, Providence, RI 02912 (e-mail: ruth_colwill@brown.edu). form of the response that is augmented by the facilitator. For example, previous studies with rats have shown that a light CS paired with a food US elicits a behavior (rearing) that is different from the behavior (headjerking) elicited by a tone CS paired with the same food US (Holland, 1977). In the feature-positive procedure used with rats, the light promoted headjerking to the tone CS, suggesting that the light did not develop its own excitatory association with the food US (Ross \& Holland, 1981). Similarly, in the facilitation procedure with pigeons, the diffuse cue was found to increase pecking to the keylight CS, rather than increasing general activity, which is the response usually evoked by simple Pavlovian pairings of a diffuse stimulus with a food US in pigeons (Rescorla, 1985). These findings suggest that a facilitator operates through a process that is different from simple excitatory conditioning. This conclusion has been reinforced by studies demonstrating that a Pavlovian excitor was not an effective substitute for a facilitator (Rescorla, 1985).

Three different modulatory mechanisms have been proposed for the action of a facilitator. The US threshold modulation account proposed by Rescorla (1985) asserts that a facilitator enables other stimuli to access the US representation by lowering its activation threshold. The specific occasion-setting account developed by Holland $(1983,1985)$ asserts that a facilitator acts as a gate on the association between a target stimulus and the US. Finally, Wagner and Brandon (1989) have argued that a facilitator engages a motivational system that modulates the response to the target stimulus. Each of these views dictates that the form of the response will be determined by the 
target, not by the facilitator. Subsequent efforts to evaluate these various proposals for how facilitators operate have depended largely on two experimental strategies; one strategy involves examining the conditions for extinction of facilitation, and the other strategy involves examining the conditions for transfer of facilitation.

Rescorla (1986a) has provided the most systematic analysis of the circumstances required for the removal of facilitation. In a series of experiments with pigeons, he found that procedures involving the nonreinforcement of an excitor, but not a neutral cue, in the presence of the facilitator successfully attenuated its power to enhance responding. In contrast, simple nonreinforcement of the facilitator left its ability to enhance responding intact, as did reinforcement of a stimulus in both the presence and the absence of the facilitator. This pattern of results suggests that the crucial feature for extinction of a facilitator is its nonreinforcement in conjunction with an excitatory Pavlovian CS. These findings reinforce the view that a facilitator is different from a Pavlovian excitor and support the idea that a facilitator modulates access to the US representation (Rescorla, 1985). This US threshold modulation framework for understanding the function of a facilitator has been further supported by the results of several studies in which transfer of facilitation was examined. In general, there is good agreement that a facilitator trained with one target will promote responding to another target trained with a different facilitator. Transfer of facilitation has also been observed for a trained and extinguished Pavlovian excitor (Holland \& Reeve, 1991; Rescorla, 1985), further suggesting that facilitation depends on a general property, such as shifting the threshold for activating the US representation.

However, it has been noted that in many of these studies, transfer of facilitation has been incomplete even to targets trained with other facilitators. This finding of incomplete transfer implies some specificity in the action of a facilitator. That specificity has been captured fairly obviously by Holland $(1983,1985)$ in his assertion that a facilitator acts selectively on the association between its target and the US. A different solution has been proposed by Brandon and Wagner (1998), who retained the idea of emotive modulation but explained the occurrence of incomplete transfer by appealing to configural control of responding. An important feature of these specific modulatory approaches is that they predict differential responding on a biconditional discrimination in which two stimulus compounds, AX and BY, are reinforced and two related compounds, $\mathrm{AY}$ and $\mathrm{BX}$, are not reinforced. In contrast, the US threshold modulation account anticipates no differential responding, because a stimulus cannot both raise and lower the threshold for activating that US representation.

The first goal of the present experiments was to demonstrate facilitation in the mouse. With the current advances in mouse genetics (Perkins, 2002; Picciotto, 1999), it is highly desirable to develop mouse conditioning procedures suitable for the analysis of the role of genes in learning and memory (Tecott, 2003; Wehner, Radcliffe,
\& Bowers, 2001). The facilitation paradigm affords an attractive opportunity to study a modulatory process that may depend on a different neural substrate from that mediating the type of simple activation process involved in Pavlovian conditioning. The second goal of the present experiments was to document the conditions for extinction and transfer of facilitation in the mouse. Evidence that the circumstances shown to remove facilitation and to produce transfer of facilitation in the pigeon have parallel effects in the mouse would suggest a common mechanism of action. Thus, current theoretical analysis of facilitation derived from studies of rats, rabbits, and pigeons could be applied directly to the mouse.

A series of experiments with $\mathrm{C} 57 \mathrm{BL} / 6 \mathrm{~J}$ mice is reported in which acquisition, extinction, and transfer of facilitation were explored. Each experiment used some elaboration of a basic training procedure that involved some trials in which a 5-sec auditory CS was embedded in the last $5 \mathrm{sec}$ of a 15 -sec light facilitator and terminated with a food pellet and other trials in which the 5-sec auditory CS was presented without food. Preliminary work in our laboratory with C57BL/6J mice has shown that Pavlovian pairings of auditory cues with food result in high rates of conditioned magazine entries, whereas light stimuli paired with food support only low to negligible rates of this response. We took advantage of this difference in assigning visual stimuli to serve as facilitators for auditory CSs, so that we could use response form to argue for a modulatory analysis of the action of the facilitator. Evidence that the light facilitator enhanced magazine entries during presentation of the auditory CS would be consistent with a modulatory account. In contrast, evidence of a low rate of responding to the auditory stimulus in the presence of the light would favor an elemental analysis in which a simple excitatory Pavlovian association developed between the light and the food. These experiments were also performed to examine how various conditions of nonreinforcement of the putative facilitator might affect its ability to augment responding to its auditory CS. Finally, these experiments were performed to examine transfer of facilitation and performance on a biconditional discrimination.

\section{EXPERIMENT 1}

The aim of Experiment 1 was to document acquisition and extinction of facilitation in the mouse. C57BL/6J mice were trained on a facilitation procedure modeled after the positive patterning procedure used by Davidson and Rescorla (1986) with rats. Thus, the subjects received reinforced presentations of a noise target embedded in the last $5 \mathrm{sec}$ of a 15 -sec light facilitator $(\mathrm{L}-\mathrm{N}+$ ) intermixed with separate nonreinforced presentations of the light facilitator $(\mathrm{L}-)$ and the noise target $(\mathrm{N}-)$. Nonreinforced presentations of the light were included in order to discourage the potential development of a Pavlovian association between the light and the food that might interfere with its ability to develop modulatory control over responding to the noise target (Rescorla, 1986b). 
Following acquisition of facilitation, half of the mice (Group I) were given conditioned inhibition (CI) training in which the light facilitator was established as a signal for the nonreinforcement of a tone that was otherwise reinforced $(\mathrm{L}-\mathrm{T}-$ and $\mathrm{T}+$ trials). The remaining mice (Group D) were given discrimination training in which the light facilitator was presented alone and nonreinforced and the tone was presented alone but reinforced $(\mathrm{L}-$ and $\mathrm{T}+$ trials). In this way, both groups received the same number of nonreinforced presentations of the light and the same number of reinforced presentations of the tone, but only Group I received nonreinforcement of the tone excitor in the presence of the light, a treatment known to be critical for extinction of facilitation. Finally, the light facilitator was tested with the noise target in both groups. According to Rescorla's (1985) US threshold modulation account, the ability of the facilitator to promote responding to the noise target should be reduced in Group I but unaffected in Group D. In contrast, specific modulatory accounts of facilitation expect neither treatment to eliminate facilitation (Brandon \& Wagner, 1998; Holland, 1989b).

\section{Method}

\section{Subjects}

The subjects were 8 male and 8 female experimentally naive C57BL/6J mice (Jackson Labs) approximately 50 days old at the start of the experiment. They were housed in same-sex pairs in plastic tubs $(27 \times 16.5 \times 12.5 \mathrm{~cm})$ on a 12:12-h light:dark cycle. Their tails were either marked with a black stripe or left unmarked, to distinguish between individuals housed together. The mice were given 1- to 2 -h daily access to food to maintain them at $85 \%$ of their freefeeding weights. Water was always available in the home cage.

\section{Apparatus \\ The apparatus consisted of eight identical mouse conditioning boxes (Med Associates) measuring $24.0 \times 20.1 \times 18.6 \mathrm{~cm}$. The two end walls of the chamber were composed of aluminum panels; the side walls and ceiling were clear polycarbonate. The floor of the chamber was composed of $0.4-\mathrm{cm}$ stainless steel rods spaced $0.6 \mathrm{~cm}$ apart. Each chamber had a recessed food magazine in the center of one end wall. Each operation of the pellet dispenser allowed a single 20-mg food pellet (Formula A; P. J. Noyes Co.) to drop onto the floor of the magazine. An infrared detector and emitter system was mounted on the inside walls of the magazine, permitting automatic recording of head entries into the magazine. \\ Each operant chamber was enclosed in a sound-attenuating and light-resistant shell, equipped with a 1-cm spy hole in the front door for observation. A houselight with diffuser (Med Associates) was mounted on the ceiling of the shell directly above the chamber. Two speakers mounted vertically on the wall opposite the food maga- zine permitted presentation of a white noise and a $2900-\mathrm{Hz}$ tone. Experimental events were controlled and recorded automatically by interfacing (Med Associates) and a 486 computer located in the same room as the conditioning chambers.}

\section{Procedure}

Magazine training. The subjects were given one session of magazine training in which 15 food pellets were delivered on a variabletime (VT) 60-sec schedule.

Facilitation training. Each session of facilitation training consisted of 24 trials, with a mean intertrial interval (ITI) of $150 \mathrm{sec}$. On 8 trials, a noise target was presented in the last $5 \mathrm{sec}$ of a $15-\mathrm{sec}$ houselight, followed by the delivery of a food pellet $(\mathrm{L}-\mathrm{N}+)$; on 8 other trials, the houselight was presented for $15 \mathrm{sec}$ and was nonreinforced $(\mathrm{L}-)$; on the remaining 8 trials, the noise target was presented for $5 \mathrm{sec}$ and was nonreinforced $(\mathrm{N}-)$. Each of these three trial types occurred equally often and in a random order within the first 12 trials of each session; the order for the remaining 12 trials of each session was a mirror image of the first 12. All the subjects received 16 sessions of facilitation training. Head entries into the food magazine were recorded automatically during all stimulus presentations and during the ITIs throughout all of the experiments.

Extinction of facilitation. The subjects were assigned to one of two groups, counterbalanced with respect to gender and matched for response rates on the three trial types at the end of facilitation training. Group I received 16 sessions of CI training. Each session contained eight nonreinforced presentations of a tone embedded in the last $5 \mathrm{sec}$ of the 15 -sec houselight $(\mathrm{L}-\mathrm{T}-$ ) and eight reinforced presentations of the 5 -sec tone alone $(\mathrm{T}+)$. Group D received 16 sessions of discrimination training. Each session contained eight nonreinforced presentations of the $15-\mathrm{sec}$ houselight $(\mathrm{L}-)$ and eight reinforced presentations of the $5-\mathrm{sec}$ tone alone $(\mathrm{T}+)$. For both groups, the order of trials was random, and the mean ITI was $150 \mathrm{sec}$. Reinforcement consisted of a single food pellet.

Testing. There were three test sessions. Each test session was identical to a facilitation training session, except that there were only 4 presentations of each of the three trial types and all the trials were nonreinforced. Thus, there were four $\mathrm{L}-\mathrm{N}-$ trials, four $\mathrm{L}-$ trials, and four $\mathrm{N}-$ trials presented in a random order with a mean ITI of $150 \mathrm{sec}$. The first test session was preceded by half a session of CI training for Group I and by half a session of discrimination training for Group D. The second test session for each group was preceded by three daily sessions of nonreinforced noise presentations, designed to reduce responding to the noise target. Each session contained 16 nonreinforced presentations of the 5-sec noise, with a mean ITI of $150 \mathrm{sec}$. Finally, the third test session was preceded by 14 days with no treatment, to allow spontaneous recovery of responding to the noise target.

\section{Results and Discussion}

\section{Facilitation Training}

Figure 1 plots performance on the facilitation task. As training progressed, responding, as indexed by head entry into the food magazine, increased substantially to the noise target in the presence of the light facilitator $(\mathrm{L}-\mathrm{N}+)$. Responding to the noise target alone $(\mathrm{N}-)$ also increased initially but then declined to the same low level of responding as that to the light alone $(\mathrm{L}-)$. By the end of training, the light facilitator promoted substantial responding to the noise target. Analysis of the terminal session of facilitation training revealed a significant difference between responding to the noise target in the presence of the light and responding to the noise target alone $[F(1,15)=33.3, p<$ $.01]$. This result suggests that responding to the auditory target was, indeed, modulated by the light facilitator.

\section{Extinction of Facilitation}

By the end of CI training, Group I was responding at a high rate to the tone when it was presented alone and at a considerably lower rate when it was presented with the light facilitator. In the half session of CI training prior to the first test, the mean response rates on $\mathrm{T}+$ and $\mathrm{L}-\mathrm{T}-$ trials were 22.1 and 3 responses per minute, respectively. This difference in response rates was significant $[F(1,7)=$ $28.5, p<.01]$. The mean rate of responding to the first 


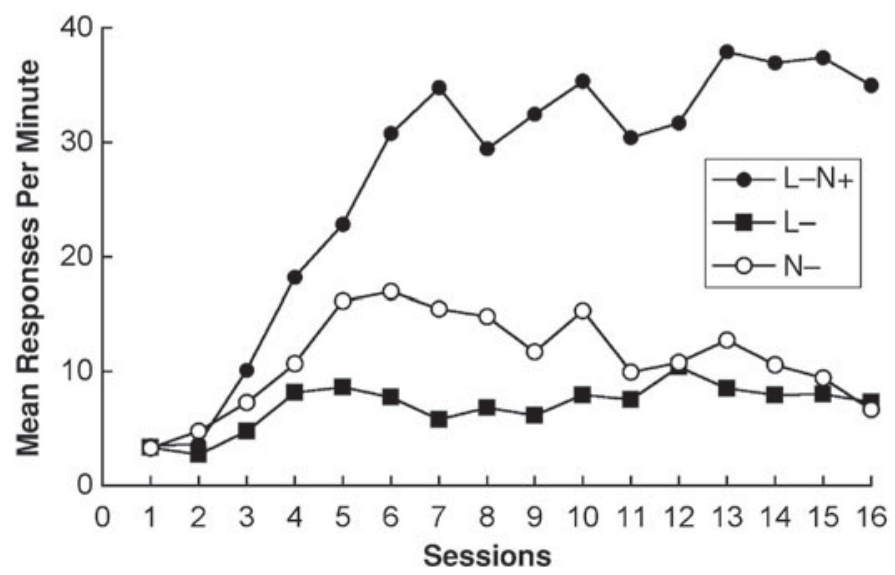

Figure 1. Experiment 1: acquisition of facilitation. Shown are the mean rates of head entries into the food magazine for an auditory target presented either alone $(\mathrm{N}-)$ or with a light facilitator $(\mathrm{L}-\mathrm{N}+)$ and during presentation of the light alone $(\mathrm{L}-)$. $\mathrm{A}$ " + " indicates reinforced, and a "-" indicates nonreinforced.

10 sec of the light on $\mathrm{L}-\mathrm{T}-$ trials was also extremely low ( 0.4 responses per minute). By the end of discrimination training, Group D was also responding at a high rate to the tone alone and at a negligible rate to the light facilitator. In the half session of discrimination training prior to the first test, the mean response rates on $\mathrm{T}+$ and $\mathrm{L}-$ trials were 27.8 and 1.5 responses per minute, respectively. This difference in response rates was significant $[F(1,7)=27.2$, $p<.01]$.

\section{Testing}

The data of most interest come from the three test sessions in which the ability of the light facilitator to promote responding to its noise target was assessed. The data from the first test session are summarized in Figure 2A. As was predicted, responding to the noise target in Group I was significantly reduced in the presence of the light. A comparison of the rates of responding to the noise alone and to the noise in the presence of the light in Group I revealed a significant difference $[F(1,7)=20.2, p<.01]$. However, there was no evidence that the light had retained its ability to promote responding to its noise target in Group D. In fact, responding to the noise target was slightly lower in the presence of the light. A comparison of the rates of responding to the noise alone and to the noise in the presence of the light in Group D revealed no significant difference $[F(1,7)=4.1, p>.05]$.

The results of the second test session, shown in Figure $2 \mathrm{~B}$, suggest that the failure to observe facilitation in Group D was not due to a ceiling effect. Even after responding to the noise had been substantially reduced to a level close to that obtained at the end of facilitation train-

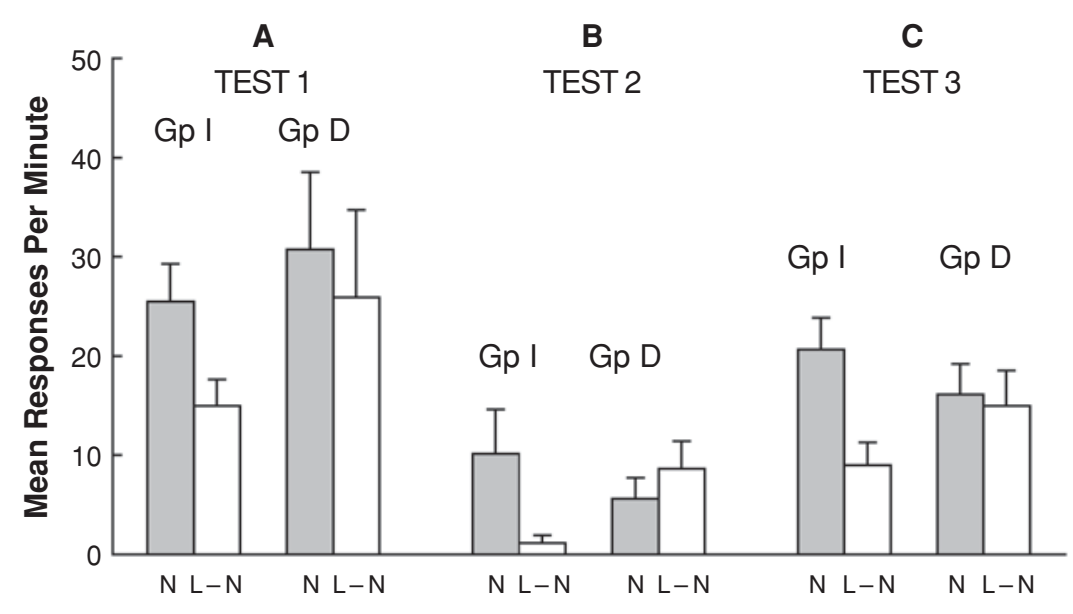

Figure 2. Experiment 1: tests of facilitation after conditioned inhibition training (Group [Gp] I) or discrimination training (Gp D). For each test (A, B, and C) and each group, responding is shown separately to the auditory target presented alone $(N)$ and in the presence of the light facilitator $(L-N)$. All the test trials were nonreinforced. 
ing, there was little evidence that the light had retained its ability to promote responding to the noise target in Group D. The mean rates of responding to the noise alone and to the noise in the presence of the light were not significantly different $[F(1,7)=1.0, p>.10]$. Despite the low response rate to the noise alone, presentation of the light in Group I continued to suppress responding to the noise target $[F(1,7)=5.6, p=.05]$.

Figure $2 \mathrm{C}$ shows the data from the third test, conducted after a 14-day rest period. As was expected, this delay was sufficient to allow responding to the noise target to recover to a level intermediate between those obtained in Tests 1 and 2. The pattern of responding to the noise in the presence and absence of the light replicates that observed in the first two tests. Responding to the noise was significantly reduced by the light in Group I $[F(1,7)=11.9$, $p<.05$ ] but was unchanged in Group $\mathrm{D}(F<1)$. Thus, a consistent set of findings emerged from these three tests, in which the level of responding to the auditory target varied across each test; a facilitator trained as an inhibitor reduced responding to the target, and a facilitator nonreinforced in a discrimination procedure lost its ability to affect responding to the target.

The results of Experiment 1 demonstrate successful acquisition of facilitation in the $\mathrm{C} 57 \mathrm{BL} / 6 \mathrm{~J}$ mouse. The light facilitator promoted magazine responses during the presentation of its noise target. This observation suggests that the light functioned as a modulator of the response to the noise, rather than simply developing its own direct Pavlovian association with the food US. Consistent with this analysis and with the results reported by Rescorla (1986a) are the test data from Group I, which revealed that training the light as a conditioned inhibitor for a Pavlovian excitor eliminated its ability to promote responding to its original auditory target. The surprising outcome of this experiment consists of the test data for Group D, which received nonreinforced presentations of the light facilitator in a simple discrimination procedure. That treatment was expected to leave the ability of the light to facilitate responding to its auditory target intact. Instead, facilitation was abolished by this treatment. Not only is this result discrepant with that in Rescorla's (1986a) study, but also it is at odds with a report by Holland (1989b) that showed no effect of nonreinforced presentations of the facilitator on its modulatory action in rats. The remainder of this article is concerned primarily with understanding the source of the discrepancy between the test results of Group D and the data reported by Rescorla (1986a) and Holland (1989b) and its implication for an analysis of facilitation in the mouse.

\section{EXPERIMENT 2}

There are a number of differences between the procedure used in Experiment 1 and the procedures used by Rescorla (1986a) and Holland (1989b) that may have contributed to the discrepancy between our results regarding the effect of nonreinforced presentations of the facilitator. First, in Experiment 1, nonreinforced presentations of the facilitator were embedded in a discrimination procedure that has been shown to sometimes endow the nonreinforced stimulus with inhibitory properties (Grossen \& Bolles, 1968; Hammond, 1967, 1968). This raises the possibility that the facilitator may have acquired sufficient inhibition to offset its response-enhancing function in Group D. Second, there were 16 sessions of extinction in Experiment 1, but only 6 sessions in the study by Rescorla (1986a) and 8 sessions in the study by Holland (1989b). Perhaps with fewer extinction sessions and the reduced opportunity to eliminate spontaneous recovery between sessions, Experiment 1 might have shown preservation of facilitation in Group D. Third, Experiment 1 did not include an untreated facilitator, so the possibility cannot be ruled out that the simple passage of time contributed to the loss of facilitation in Group D.

Experiment 2 was designed to document the effect of the passage of time on facilitation in the mouse and to assess the impact of a more abbreviated series of nonreinforced presentations of the facilitator on its ability to promote responding to its auditory target. Experiment 2 also eliminated the discrimination component of the nonreinforced treatment. C57BL/6J mice were trained on the same facilitation procedure as that used in Experiment 1. Thus, they received reinforced presentations of a noise target embedded in the last $5 \mathrm{sec}$ of a 15 -sec light facilitator $(\mathrm{L}-\mathrm{N}+)$ intermixed with separate nonreinforced presentations of the light facilitator $(\mathrm{L}-$ ) and the noise target $(\mathrm{N}-)$. Six days after the last training session, the mice were given a retention test that was identical to a facilitation training session, except that no food reinforcement was given. The purpose of this test was to determine how well facilitation would be preserved over time.

Following retention testing and subsequent retraining on the facilitation task, half of the mice (Group E) were given six extinction sessions in which the light facilitator was presented and nonreinforced. The remaining mice (Group C) were given context exposure. They were placed in the operant boxes but did not receive any stimulus presentations. In this way, both groups were exposed to the context without reinforcement, but only Group E received nonreinforced presentations of the facilitator. Finally, the light facilitator was tested with the noise target in both groups. The question of interest was whether facilitation would be undermined by nonreinforcement of the facilitator.

\section{Method \\ Subjects and Apparatus \\ Sixteen experimentally naive male C57BL/6J mice (Jackson Labs), approximately 50 days old at the start of the experiment, served as subjects. The conditions for housing and maintenance were the same as those in Experiment 1. The apparatus was the same} as that used in Experiment 1.

\section{Procedure}

Magazine training. The subjects were given two sessions of magazine training, in each of which 15 food pellets were delivered on a VT 60 -sec schedule.

Facilitation training. The procedure for facilitation training was identical to that used in Experiment 1. Each of the 16 sessions con- 
sisted of eight $\mathrm{L}-\mathrm{N}+$ trials, eight $\mathrm{L}-$ trials, and eight $\mathrm{N}-$ trials. The mean ITI was $150 \mathrm{sec}$.

Retention test. For 6 days after the terminal session of facilitation training, the mice remained in the colony, were weighed daily, and were maintained at their $85 \%$ ad lib body weight. The following day, they were tested for retention of the facilitation task. The test session was identical to a regular facilitation training session, except that all the trials were nonreinforced.

Extinction of facilitation. Following the retention test, the subjects were given two additional sessions of facilitation training. The subjects were subsequently assigned to one of two groups matched for response rates on the three trial types in the second of these facilitation retraining sessions. Group E received six extinction sessions. Each session contained 16 nonreinforced presentations of the 15-sec houselight facilitator $(\mathrm{L}-)$, during which magazine entries were recorded. Group $\mathrm{C}$ received six sessions of context exposure. They were placed in the operant boxes for the same amount of time as Group E but received no stimulus presentations. For Group C, there were 16 pseudotrials scheduled at the same time as an Ltrial, during which magazine entries were recorded. The mean ITI was $150 \mathrm{sec}$ for both groups.

Testing. All the subjects were given another test session that was identical to a regular facilitation training session, except that all the trials were nonreinforced.

\section{Results and Discussion}

\section{Facilitation Training}

Acquisition of the facilitation task followed a course similar to that observed in Experiment 1. As training progressed, responding increased substantially to the noise target in the presence of the light facilitator $(\mathrm{L}-\mathrm{N}+)$. Responding to the noise target alone $(\mathrm{N}-)$ also increased initially but then declined to the same low level of responding as that to the light alone $(\mathrm{L}-)$. By the end of training, the light facilitator promoted substantial responding to the noise target. In the final training session, the mean rate of responding was 9.9 responses per minute to the target alone and 41.3 responses per minute to the target in the presence of the facilitator. The mean rate of responding to the facilitator alone was 12 responses per minute. Analysis of the terminal session of facilitation training revealed a significant difference between responding to the noise target in the presence of the light and responding to the noise target alone $[F(1,15)=43.2, p<.01]$.

\section{Retention Test}

Figure $3 \mathrm{~A}$ shows the data from the retention test conducted after a 6-day rest period (Test 1). Although there was a slight decrease in responding to the noise target in the presence of the facilitator, relative to the end of facilitation training, responding to the noise was nevertheless significantly and substantially enhanced by the light $[F(1,15)=50.7, p<.01]$.

\section{Extinction of Facilitation}

Over the course of extinction training, responding to the light facilitator in Group E decreased slightly from its initially low level of 5.7 responses per minute in Session 1 to fewer than 2 responses per minute for the remaining five sessions of extinction. In the final session of extinction, the mean response rate on $\mathrm{L}-$ trials was 0.8 responses per minute. For Group C, the mean rate of magazine entries on the pseudotrials declined from 2.4 responses per minute in Session 1 to under 2 responses per minute for the subsequent sessions. In the final session of extinction, the mean response rate on the pseudotrials was 1.4 responses per minute.

\section{Testing}

The data of most interest come from the postextinction test, in which the ability of the light facilitator to promote responding to its noise target was assessed. The data from this session (Test 2) are summarized for each group in Figure $3 \mathrm{~B}$. As was predicted, responding to the noise target in Group $\mathrm{C}$ was promoted in the presence of the light. The

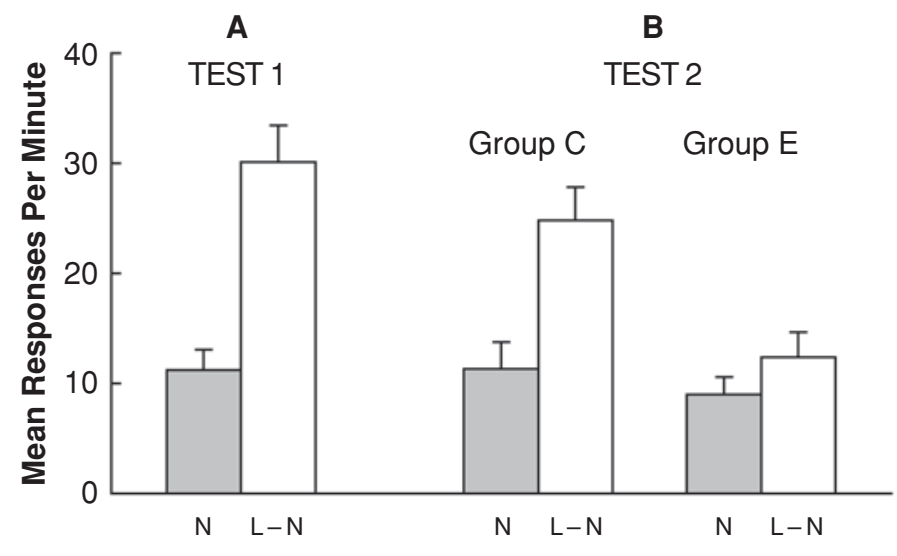

Figure 3. Experiment 2: (A) retention test of facilitation (Test 1) and (B) postextinction test of facilitation (Test 2). For each test, responding is shown separately to the auditory target presented alone $(\mathrm{N})$ and in the presence of the light facilitator $(\mathrm{L}-\mathrm{N})$. For the postextinction test, responding is shown separately for the animals that received nonreinforced presentations of the facilitator (Group E) and for the animals simply exposed to the context (Group C). All the test trials were nonreinforced. 
magnitude of this enhancement effect was only slightly less than that observed in the retention test. A comparison of the rates of responding to the noise alone and to the noise in the presence of the light in Group $C$ revealed a significant difference $[F(1,7)=29.5, p<.01]$. However, there was no evidence that the light had retained its ability to promote responding to its noise target in Group E. Responding to the noise target was only marginally elevated in the presence of the light. A comparison of the rates of responding to the noise alone and to the noise in the presence of the light in Group E revealed no significant difference $[F(1,7)=1.9, p>.10]$.

The results of Experiment 2 confirm and extend the findings of Experiment 1 regarding acquisition and extinction of facilitation in the C57BL/6J mouse. First, the light facilitator promoted magazine responses during the presentation of its noise target, suggesting that the light functioned as a modulator of the response to the noise, rather than simply developing its own direct Pavlovian association with the food US. Second, this enhancement effect persisted over time. At the end of a 6-day rest period, the mice continued to respond more to the noise target in the presence of the facilitator than in its absence. Third, the light facilitator failed to promote responding to its auditory target following simple nonreinforced presentation and after only six sessions of extinction. This loss of the enhancement effect cannot be attributed either to the passage of time or to context exposure per se, because facilitation was preserved in Group C. These results, together with those of Experiment 1, suggest that nonreinforced presentations of the facilitator can decrease its ability to promote responding to its original target.

\section{EXPERIMENT 3A}

The primary goal of Experiment $3 \mathrm{~A}$ was to provide a further assessment of the effect of nonreinforced presentations of the facilitator on its response-enhancing function, using a within-subjects design. To this end, the mice were initially trained with two visual facilitators (L1 and L2) and two auditory targets ( $\mathrm{N}$ and $\mathrm{T}$ ). They were subsequently exposed to presentations of one facilitator alone, without reinforcement. Both facilitators were then tested with both targets. The basic design of this experiment is outlined in Table 1.

An important advantage of this within-subjects design is that any difference between the two facilitators during testing can be attributed to a specific, rather than generalized, effect of the extinction treatment. It also more closely parallels the design used by Rescorla (1986a). Experiment $3 \mathrm{~A}$ also omitted nonreinforced presentations of the facilitators during original training. Although it seems more, rather than less, likely that the inclusion of such trials would have minimized any impact of additional nonreinforced presentations of a facilitator on target responding, it constituted a major procedural difference between the feature-positive procedure used by Rescorla (1986a) and Holland (1989b) and the positive patterning
Table 1

Basic Design of Experiment 3A

\begin{tabular}{ccc}
\hline Facilitation Training & Extinction & Testing \\
\hline $\mathrm{L} 1-\mathrm{N}+, \mathrm{L} 2-\mathrm{N}+, \mathrm{N}-$ & $\mathrm{L} 1-$ or $\mathrm{L} 2-$ & $\mathrm{L} 1-\mathrm{N}-, \mathrm{L} 2-\mathrm{N}-, \mathrm{N}-$ \\
$\mathrm{L} 1-\mathrm{T}+, \mathrm{L} 2-\mathrm{T}+, \mathrm{T}-$ & & $\mathrm{L} 1-\mathrm{T}-, \mathrm{L} 2-\mathrm{T}-, \mathrm{T}-$ \\
\hline
\end{tabular}

Note-Two 15-sec lights (L1 and L2) were established as facilitators for a 5-sec noise (N) and a 5-sec tone (T) target. In the extinction phase, one of the facilitators was presented alone and nonreinforced. In the test phase, responding to the targets alone ( $\mathrm{N}$ and $\mathrm{T}$ ) was compared with responding to the targets in the presence of the extinguished and untreated facilitators. A "+" indicates reinforced, and a "-" indicates nonreinforced.

procedure used in Experiments 1 and 2. The question of interest was whether simple nonreinforced presentations of a facilitator would eliminate its response-enhancing function.

\section{Subjects and Apparatus \\ Method \\ Sixteen experimentally naive male C57BL/6J mice (Jackson Labs), approximately 50 days old at the start of the experiment, served as subjects. The conditions for housing and maintenance were the same as those in Experiment 1. The apparatus was the same as that used in Experiment 1, except for the addition of a 28- $\mathrm{V}$ yel- low stimulus panel light mounted $2 \mathrm{~cm}$ above the grid floor on the back polycarbonate wall and $3 \mathrm{~cm}$ from the right aluminum wall that supported the recessed food magazine.}

\section{Procedure}

Magazine training. The subjects were given one session of magazine training, in each of which 15 food pellets were delivered on a VT 60 -sec schedule.

Facilitation training. Each of the 16 sessions of facilitation training consisted of twelve 5-sec presentations of each auditory target, noise $(\mathrm{N})$ and tone $(\mathrm{T})$, with a mean ITI of $150 \mathrm{sec}$. Four presentations of each auditory target were embedded in the last $5 \mathrm{sec}$ of a $15-\mathrm{sec}$ houselight $(\mathrm{L} 1-\mathrm{N}+$ and $\mathrm{L} 1-\mathrm{T}+)$, and another four presentations of each cue were embedded in the last $5 \mathrm{sec}$ of a $15-\mathrm{sec}$ panel light (L2-N+ and $\mathrm{L} 2-\mathrm{T}+$ ). All of these presentations terminated with the delivery of a food pellet. In addition, four presentations of each auditory target were nonreinforced $(\mathrm{N}-$ and $\mathrm{T}-$ ). An equal number of each of the six trial types occurred in the first half of each session, with the order randomized across days. The order of trials in the second half of each session was a mirror image of the order in the first half of that session.

Extinction of facilitation. For the next 6 days, the subjects received nonreinforced presentations of one of the light facilitators. Each session contained either 16 nonreinforced presentations of the 15 -sec houselight (L1-) or 16 nonreinforced presentations of the 15 -sec panel light (L2-). Eight mice were assigned to each treatment condition, matched for their response rates on the six trial types in the terminal session of facilitation training. The mean ITI was $150 \mathrm{sec}$.

Testing. All the subjects were given one test session that was identical to a facilitation training session, except that all the trials were nonreinforced.

\section{Results and Discussion \\ Facilitation Training}

Figure 4 plots responding to the auditory targets presented alone ( $\mathrm{Tar}-)$ and in the presence of the facilitators (Fac-Tar + ) across the 16 sessions of facilitation training. 


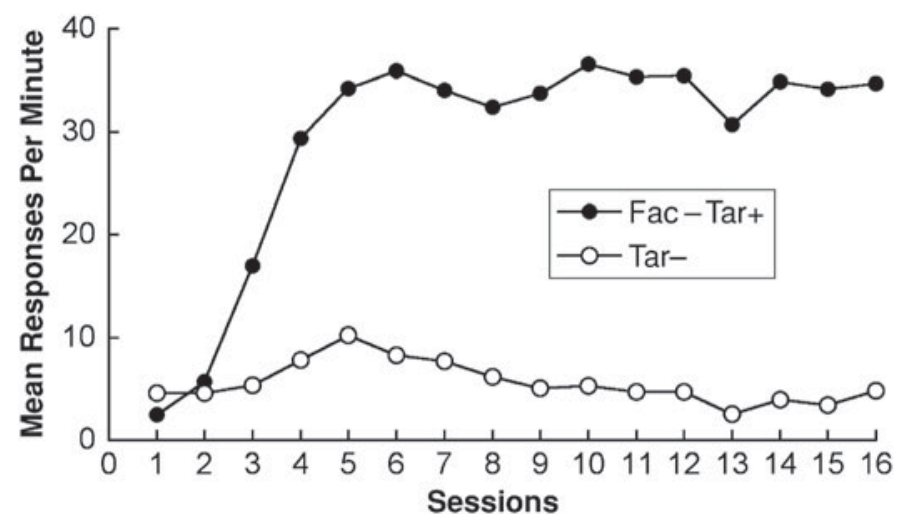

Figure 4. Experiment 3A: acquisition of facilitation. Shown are the mean rates of head entries into the food magazine during the auditory targets presented either alone (Tar-) or with the light facilitators (Fac-Tar+). A "+" indicates reinforced, and a " $-"$ indicates nonreinforced.

Both the pattern of acquisition and the terminal rates of responding to the facilitator-target compound and to the target alone were similar to those obtained in Experiments 1 and 2. As training progressed, responding increased substantially to the auditory targets in the presence of each facilitator. Responding to the targets alone showed a slight initial increase but then declined to a rate slightly lower than that recorded in the first $10 \mathrm{sec}$ of the light facilitators. By the end of training, the facilitators promoted substantial responding to the targets. Analysis of the terminal session of facilitation training revealed a significant difference between responding to the auditory targets in the presence of the visual facilitators and responding to the targets alone $[F(1,15)=108.6, p<.01]$.

\section{Extinction of Facilitation}

Over the course of extinction training, responding to the facilitator decreased slightly from its initially low level of 3.1 responses per minute in Session 1 to under 2 responses per minute for the remaining five sessions of ex- tinction. Once again, both the overall pattern and the level of responding to the facilitator alone were similar to those observed in Experiments 1 and 2. In the final session of extinction, the mean response rate was 0.4 responses per minute.

\section{Testing}

The data of most interest come from the postextinction test, in which the ability of the extinguished and notpresented facilitators to promote responding to the auditory targets was assessed. The data from this session are summarized in Figure 5. Although the overall levels of responding are extremely low, responding to the targets was increased by both facilitators, but more so by the untreated facilitator than by the extinguished facilitator. A comparison of the rates of responding to the targets alone and to the targets in the presence of the extinguished and untreated facilitators revealed a significant main effect of conditions $[F(2,30)=13.8, p<.01]$. Follow-up analyses revealed that responding to the targets was promoted by

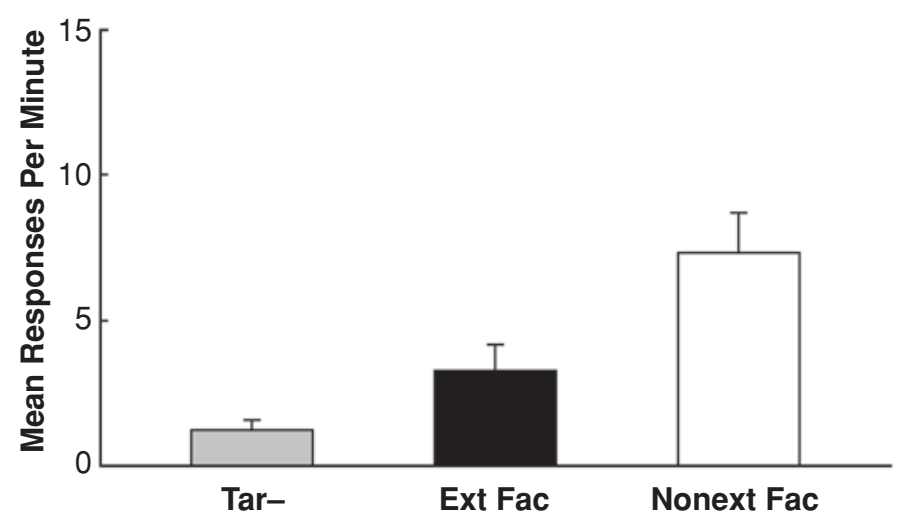

Figure 5. Experiment 3A: mean responses per minute during the postextinction test of facilitation. Responding is shown separately to the auditory targets presented alone (Tar-) and in the presence of a facilitator that had been extinguished (Ext Fac) or not treated (Nonext Fac). All the test trials were nonreinforced. 
both the untreated facilitator $[F(1,15)=21.0, p<.01]$ and the extinguished facilitator $[F(1,15)=5.2, p<.05]$. However, responding to the targets was also significantly higher in the presence of the untreated facilitator, relative to that of the extinguished facilitator $[F(1,15)=10.2, p<$ $.01]$.

In summary, the results of Experiment $3 \mathrm{~A}$ confirmed with a feature-positive procedure the results of Experiments 1 and 2, which used a positive patterning procedure, that facilitation is reduced by nonreinforced presentations of the facilitator. With a within-subjects design, Experiment 3A demonstrated that a facilitator that had been presented alone and nonreinforced was less effective than an untreated facilitator in promoting responding to an auditory target. Unfortunately, the level of responding to the auditory targets during testing with the untreated facilitator was considerably lower than the rate observed during the terminal sessions of facilitation training. This outcome suggests that there may have been substantial generalization between the two facilitators, so that the impact of nonreinforced presentations on one facilitator generalized to the other (untreated) facilitator. This degree of stimulus generalization may constrain the use of a within-subjects design with these particular stimuli in C57BL/6J mice. Nevertheless, the difference between the extinguished and the untreated facilitators indicates that the response-enhancing properties of a facilitator can be reduced by simple nonreinforcement.

\section{EXPERIMENT 3B}

Using a positive patterning training procedure to establish facilitation, Experiment 1 showed that facilitation was removed by training the facilitator in a CI procedure. The main goal of Experiment 3B was to determine whether this result could be replicated using a feature-positive training procedure to establish facilitation. We also sought to inspect further the extent to which generalization between the current stimuli might limit their use in a withinsubjects design. The mice from Experiment $3 \mathrm{~A}$ were first retrained on the original facilitation tasks. Then one of the facilitators was repeatedly presented in conjunction with one of the targets and was nonreinforced, while that target alone was reinforced; the other facilitator and the other target were spared this treatment. Assignment of the facilitators to these two treatment conditions was orthogonal to their treatment (extinguished or not) in Experiment 3A.
Both facilitators were then tested with both targets. The basic design of this experiment is outlined in Table 2. The question of interest was whether nonreinforced presentations of a facilitator in conjunction with one of the targets would eliminate its response-enhancing function.

\section{Method \\ Subjects and Apparatus \\ In Experiment 3B, the same mice and apparatus as those in Exper- iment $3 \mathrm{~A}$ were used. The conditions for housing and maintenance of the animals were the same as those in Experiment 1.}

\section{Procedure}

Facilitation retraining. Each of the eight sessions of facilitation retraining consisted of twelve 5 -sec presentations of each auditory target, noise (N) and tone (T), with a mean ITI of $150 \mathrm{sec}$. Four presentations of each auditory target were embedded in the last $5 \mathrm{sec}$ of a $15-\mathrm{sec}$ houselight $(\mathrm{L} 1-\mathrm{N}+$ and $\mathrm{L} 1-\mathrm{T}+)$, and another four presentations of each cue were embedded in the last $5 \mathrm{sec}$ of a $15-\mathrm{sec}$ panel light $(\mathrm{L} 2-\mathrm{N}+$ and $\mathrm{L} 2-\mathrm{T}+)$. All of these presentations terminated with the delivery of a food pellet. In addition, four presentations of each auditory target were nonreinforced $(\mathrm{N}-$ and $\mathrm{T}-$ ). An equal number of each of the six trial types occurred in the first half of each session, with the order randomized across days. The order of trials in the second half of each session was a mirror image of the order in the first half of that session.

Extinction of facilitation: Conditioned inhibition training Following facilitation retraining, one of the facilitators was subsequently trained in a CI procedure with the noise target for the next 16 days. Each session contained eight nonreinforced presentations of the noise target embedded in the last $5 \mathrm{sec}$ of one of the $15-\mathrm{sec}$ light facilitators $(\mathrm{L} 1-\mathrm{N}-$ or $\mathrm{L} 2-\mathrm{N}-$ ) and eight reinforced presentations of the 5 -sec noise alone $(\mathrm{N}+)$. For 8 animals, L1 was assigned to be treated, and for the other 8 animals, L2 was assigned to be treated. Assignment of which facilitator was to be treated was orthogonal to its extinction treatment in Experiment 3A. Thus, for half the animals, L1 or L2 was the previously extinguished facilitator, and for the other half, L1 or L2 was the previously untreated facilitator. The order of trials was randomized, and the mean ITI was $150 \mathrm{sec}$.

Testing. All the subjects were given a test session that was identical to a facilitation retraining session, except that all the trials were nonreinforced.

\section{Results and Discussion}

\section{Facilitation Retraining}

Retraining was effective in reestablishing control of responding to the targets by the facilitators. Analysis of the terminal session of facilitation training revealed that responding to the auditory targets in the presence of the visual facilitators was substantially higher than respond-

Table 2

Basic Design of Experiment 3B

\begin{tabular}{ccc}
\hline Facilitation Retraining & $\begin{array}{c}\text { Extinction: Conditioned } \\
\text { Inhibition Training }\end{array}$ & Testing \\
\hline $\mathrm{L} 1-\mathrm{N}+, \mathrm{L} 2-\mathrm{N}+, \mathrm{N}-$ & $\mathrm{L} 1-\mathrm{N}-, \mathrm{N}+$ or $\mathrm{L} 2-\mathrm{N}-, \mathrm{N}+$ & $\mathrm{L} 1-\mathrm{N}-, \mathrm{L} 2-\mathrm{N}-, \mathrm{N}-$ \\
$\mathrm{L} 1-\mathrm{T}+, \mathrm{L} 2-\mathrm{T}+, \mathrm{T}-$ & & $\mathrm{L} 1-\mathrm{T}-, \mathrm{L} 2-\mathrm{T}-, \mathrm{T}-$ \\
\hline
\end{tabular}

Note-After retraining the facilitators (L1 and L2) with the auditory targets ( $\mathrm{N}$ and T), one of the facilitators (counterbalanced across subjects) was trained as a conditioned inhibitor with $\mathrm{N}$. In the test phase, responding to the targets alone ( $\mathrm{N}$ and $\mathrm{T}$ ) was compared with responding to the targets in the presence of L1 and L2. A "+" indicates reinforced, and a "- " indicates nonreinforced. 
ing to the targets alone. The mean rate of responding to the targets alone was 5.4 responses per minute. In the presence of the facilitator that had been extinguished in Experiment $3 \mathrm{~A}$, this rate increased to 41.9 responses per minute $[F(1,15)=47.9, p<.01]$, and in the presence of the facilitator that was not extinguished in Experiment 3A, this rate increased to 40.9 responses per minute $[F(1,15)=$ $53.9, p<.01]$. There was no significant difference between the previously extinguished and nonextinguished facilitators in promoting responding to the targets at the end of retraining $(F<1)$.

\section{Extinction of Facilitation: Conditioned Inhibition Training}

By the final session of CI training, responding to the reinforced target alone had substantially increased, and responding to that target in the presence of the facilitator had substantially decreased. In the last session of CI training, the mean rates of responding to the target alone and the target in the presence of the facilitator were 29.1 and 12.1 responses per minute, respectively. This difference was statistically significant $[F(1,15)=37.7, p<.01]$.

\section{Testing}

The test data are summarized in Figure 6: Mean responding to the auditory target (noise) used for CI training is shown in Figure 6A, and mean responding to the untreated auditory target (tone) is shown in Figure 6B. For each target, the mean response rate is plotted for the facilitator trained as an inhibitor (FacI), for the control facilitator (FacC), and for the target alone (Tar-). Both facilitators depressed responding to the targets, but the facilitator trained as a conditioned inhibitor suppressed responding more than did the control facilitator. The data were collapsed across subjects as a function of whether the facilitator trained as a $\mathrm{CI}$ in Experiment $3 \mathrm{~B}$ had been nonreinforced or not in Experiment 3A, because that factor was found to be statistically nonsignificant $(F<1)$. A two-way repeated measures ANOVA showed a significant main effect of trial type $[F(2,30)=27.7, p<.01]$ but no significant main effect of target type $(F<1)$ and no significant interaction $[F(2,30)=1.6, p>.10]$. Exploration of the significant main effect of trial type revealed that both FacI and FacC depressed responding to the auditory targets $[F(1,15)=$ 51.0 and $F(1,15)=23.2$, respectively; $p \mathrm{~s}<.01]$ and that the depression in responding was greater in the presence of FacI, relative to that of FacC $[F(1,15)=6.7, p=$ .021].

Using a conventional feature-positive procedure to establish facilitation, Experiment 3B confirmed that a facilitator trained as a conditioned inhibitor lost its ability to promote responding to a target stimulus and, instead, reduced responding to that target stimulus. This finding is consistent with prior work on the conditions that produce extinction of facilitation; facilitation is abolished by nonreinforcement of the facilitator in conjunction with an excitatory Pavlovian CS (Rescorla, 1986a). However, as was observed in Experiments 1 and $3 \mathrm{~A}$, there was considerable stimulus generalization between the auditory stimuli and between the lights, respectively. Consequently, reinforcing one auditory target (tone) resulted in elevated responding to the other auditory target (noise) in Experiment 1, and decremental training of one facilitator resulted in a similar decrement in the control (untreated) facilitator in Experiments $3 \mathrm{~A}$ and $3 \mathrm{~B}$, albeit to a lesser degree. It is important to note that the occurrence of such
A

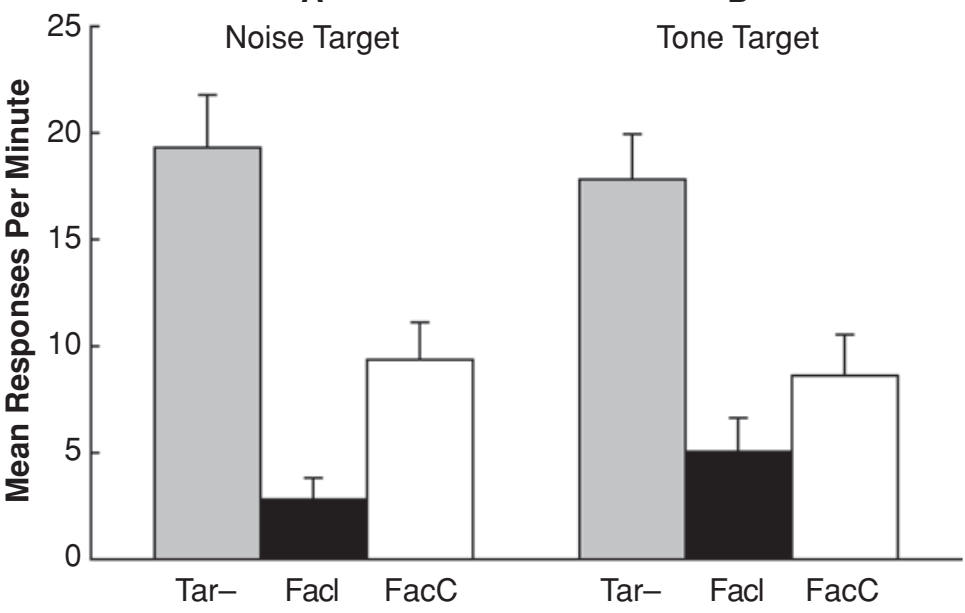

Figure 6. Experiment 3: mean responses per minute during the postconditioned inhibition test of facilitation. Panel A shows responding to the noise target that was used for conditioned inhibition training when it was presented alone (Tar-) and with the facilitator that either was used for conditioned inhibition training (FacI) or was not treated (FacC). Panel B shows responding to the untreated tone target presented alone (Tar-) and with the facilitator that was either trained as a conditioned inhibitor (FacI) or not treated (FacC). All the test trials were nonreinforced. 
generalization does not necessarily undermine the conclusions that we have drawn about extinction of facilitation, because the effect of the treated facilitator was significantly different statistically from that of the control facilitator. However, it does complicate assessment of how much of the absolute loss of facilitation can be attributed to a specific effect of the decremental treatment, as opposed to a nonspecific effect of that treatment. Moreover, it raises concerns about assessment and interpretation of transfer of facilitation across targets. These issues were taken up in the next experiment.

\section{EXPERIMENT 4}

The results of the preceding experiments are in partial agreement with modulatory accounts of facilitation. On the one hand, the high rate of magazine responding to the auditory target in the presence of the light facilitator is consistent with all of the modulatory models. The detrimental effect of converting the facilitator into a conditioned inhibitor fits, in particular, with the US threshold modulation analysis of facilitation. On the other hand, the profound attenuation of facilitation following nonreinforced presentations of the facilitator is not anticipated by any modulatory approach. The main aim of Experiment 4 was to procure additional support for modulatory learning in the mouse. One strategy we used was to look for evidence of transfer of facilitation across targets. In other work, evidence that a facilitator trained with one target will subsequently promote responding to a different target trained with another facilitator has encouraged an analysis of facilitation that depends on a general property, such as shifting the threshold for activating the US representation (Rescorla, 1985, 1986a). The other approach we used was to apply the assessments we have made of facilitation to CI. There is considerable evidence from other studies that CI is most appropriately understood in terms of a modulatory process (e.g., Holland, 1989c, 1992; Rescorla, 1985; Rescorla \& Holland, 1977).

A standard procedure for assessing transfer of facilitation has been to train each of two facilitators with its own target and then to test each facilitator with the other's target (Davidson \& Rescorla, 1986; Rescorla, 1985). Such a design is unlikely to be useful in the present case, because of stimulus generalization. Although, in the present experiments, we used stimuli that we have found, in other studies in our laboratory, to be readily discriminable by the C57BL/6J mouse, there was nevertheless considerable generalization between the two auditory stimuli (noise and tone) and between the two visual stimuli (houselight and panel light). This problem was particularly acute in Experiments $3 \mathrm{~A}$ and $3 \mathrm{~B}$, where the common treatment of the two visual facilitators and the two auditory targets in facilitation training may have especially deterred discrimination between stimuli of the same modality. Partly in an attempt to mitigate this problem of stimulus generalization, in Experiment 4 we used a design in which mice were given facilitation training with one light and one auditory target and inhibition training with a different light and a different auditory target. Such differential treatment of the same-modality stimuli in training was expected to reduce the generalization between them. Transfer of facilitation was subsequently evaluated by testing the facilitator with the target trained with the inhibitor. However, in the initial transfer tests, responding to the target trained with the inhibitor was too high to permit detection of any significant increase by the facilitator. To provide a more meaningful assessment of transfer of facilitation, responding to the target was reduced by presenting that target without reinforcement prior to final transfer testing of that facilitator and target.

The design used in Experiment 4 also permitted examination of the merits of a modulatory analysis of CI performance. Holland (1984, 1985) and Rescorla (1985, 1986a, 1987) have suggested that it is profitable to view inhibition as the opposite of facilitation. Indeed, the present experiments showing that facilitation is eliminated by training the facilitator as an inhibitor corroborate this view. Additional support for the modulatory account of inhibition has come from studies demonstrating transfer of inhibition across targets (Holland \& Lamarre, 1984; Rescorla \& Holland, 1977) and the preservation of inhibitory function after nonreinforced presentations of the inhibitor (Rescorla, 1985; Witcher \& Ayres, 1984; Zimmer-Hart \& Rescorla, 1974). Consequently, both transfer of inhibition and the effect of nonreinforced presentations of the inhibitor were assessed in Experiment 4.

The basic design of Experiment 4 is illustrated in Table 3. The subjects received facilitation training with one of the lights and one of the auditory targets (L1-A1+, A1-) and inhibitory training with the other light and the other auditory target $(\mathrm{L} 2-\mathrm{A} 2-, \mathrm{A} 2+)$. Each light was then tested with each auditory target to assess the ability of the lights to transfer across targets. Testing was followed

Table 3

Basic Design of Experiment 4

\begin{tabular}{|c|c|c|c|c|c|}
\hline Fac and Inh & Testing & Extinction & Testing & Tar Rev & Testing \\
\hline $\begin{array}{l}\mathrm{L} 1-\mathrm{A} 1+, \mathrm{A} 1- \\
\mathrm{L} 2-\mathrm{A} 2-, \mathrm{A} 2+\end{array}$ & $\begin{array}{l}\mathrm{L} 1-\mathrm{A} 1-, \mathrm{L} 2-\mathrm{A} 1- \\
\mathrm{A} 1-, \mathrm{A} 2- \\
\mathrm{L} 1-\mathrm{A} 2-\mathrm{L} 2-\mathrm{A} 2-\end{array}$ & $\mathrm{L} 1-$ or L2- & $\begin{array}{l}\mathrm{L} 1-\mathrm{A} 1-, \mathrm{L} 2-\mathrm{A} 1- \\
\mathrm{A} 1-, \mathrm{A} 2- \\
\mathrm{L} 1-\mathrm{A} 2-\mathrm{L} 2-\mathrm{A} 2-\end{array}$ & $\mathrm{A} 1+, \mathrm{A} 2-$ & $\begin{array}{l}\mathrm{L} 1-\mathrm{A} 1-, \mathrm{L} 2-\mathrm{A} 1- \\
\mathrm{A} 1-, \mathrm{A} 2- \\
\mathrm{L} 1-\mathrm{A} 2-\mathrm{L} 2-\mathrm{A} 2-\end{array}$ \\
\hline
\end{tabular}

Note-All the subjects were trained with one light (L1) as a facilitator (Fac) for one auditory target (A1) and another light (L2) as an inhibitor (Inh) for a different auditory target (A2). In the extinction phase, one of the lights (counterbalanced across subjects) was presented and nonreinforced. In the target reversal (Tar Rev) phase, the target (A1) trained with the facilitator was reinforced, and the target (A2) trained with the inhibitor was nonreinforced. In the test phases, each light was tested with each auditory target. A “+” indicates reinforced, and a "-" indicates nonreinforced. 
by retraining (not shown) and then by a series of extinction sessions in which either L1 or L2 was presented alone and nonreinforced. Testing was then repeated in order to examine the impact of these nonreinforced presentations on facilitation and inhibition. Additional facilitation and inhibition retraining sessions followed (not shown), prior to a final transfer test. This final test was preceded by target training with the reverse reinforcement contingencies, so that the target trained with the inhibitor was nonreinforced (to reduce responding) and the target trained with the facilitator was reinforced (to increase responding). It was expected that this adjustment in the level of responding to the targets would improve detection of transfer of facilitation and inhibition.

\section{Method}

\section{Subjects and Apparatus}

Thirty-two experimentally naive male C57BL/6J mice (Jackson Labs), approximately 50 days old at the start of the experiment, served as subjects. One subject died during the retraining phase after the first transfer test; his data were excluded from analysis from that point forward. The conditions for housing and maintenance were the same as those in Experiment 1. The apparatus was the same as that used in Experiments 3A and 3B.

\section{Procedure}

Magazine training. The subjects were given two sessions of magazine training, in each of which 15 food pellets were delivered on a VT 60 -sec schedule.

Facilitation and inhibition training. Each of the 20 sessions of concurrent facilitation and inhibition training consisted of 24 trials designed to establish either L1 or L2 as a facilitator for one auditory target and the other as a conditioned inhibitor for a different auditory target. Eight subjects received 6 trials each of $\mathrm{L} 1-\mathrm{N}+, \mathrm{N}-$, $\mathrm{L} 2-\mathrm{T}-, \mathrm{T}+; 8$ subjects received 6 trials each of $\mathrm{L} 1-\mathrm{T}+, \mathrm{T}-$, $\mathrm{L} 2-\mathrm{N}-, \mathrm{N}+; 8$ subjects received 6 trials each of $\mathrm{L} 2-\mathrm{N}+, \mathrm{N}-$, $\mathrm{L} 1-\mathrm{T}-, \mathrm{T}+$; and 8 subjects received 6 trials each of $\mathrm{L} 2-\mathrm{T}+, \mathrm{T}-$, $\mathrm{L} 1-\mathrm{N}-, \mathrm{N}+$. The auditory targets $(\mathrm{N}$ and $\mathrm{T})$ were always $5 \mathrm{sec}$ long, and L1 and L2 were always $15 \mathrm{sec}$ long. On trials in which $\mathrm{N}$ and $\mathrm{T}$ were accompanied by L1 or L2, they were embedded in the last $5 \mathrm{sec}$ of the 15 -sec light. Reinforced trials terminated with a food pellet $(+)$. An equal number of each of the four trial types occurred in the first half of each session, with the order randomized across days. The order of trials in the second half of each session was a mirror image of the order in the first half of that session. The mean ITI was $150 \mathrm{sec}$.

Transfer test. The following day, all the subjects received a transfer test containing four nonreinforced presentations of each auditory target alone ( $\mathrm{N}-$ and $\mathrm{T}-$ ), with $\mathrm{L} 1(\mathrm{~L} 1-\mathrm{N}-$ and $\mathrm{L} 1-\mathrm{T}-)$, and with $\mathrm{L} 2(\mathrm{~L} 2-\mathrm{N}-$ and $\mathrm{L} 2-\mathrm{T}-)$. The mean ITI was $150 \mathrm{sec}$.

Facilitation and inhibition retraining. There were six sessions of concurrent facilitation and inhibition training identical to those used for original training.

Extinction and testing. There were six extinction sessions, each of which contained 16 nonreinforced presentations of either the 15 -sec facilitator or the 15 -sec inhibitor with a mean ITI of $150 \mathrm{sec}$. Assignment of the mice to extinction of either the facilitator or the inhibitor was based on their performance in the final session of retraining and was counterbalanced across stimulus identity (houselight or panel light). There were 16 mice in the inhibitor extinction condition and 15 mice in the facilitation extinction condition matched for response rates on the four trial types in the terminal session of facilitation and inhibition training. The day after the last extinction session, the subjects were given a transfer test. As before, this test session contained four nonreinforced presentations of each auditory target alone $(\mathrm{N}-$ and $\mathrm{T}-)$, with $\mathrm{L} 1(\mathrm{~L} 1-\mathrm{N}-$ and $\mathrm{L} 1-\mathrm{T}-$ ), and with $\mathrm{L} 2(\mathrm{~L} 2-\mathrm{N}-$ and $\mathrm{L} 2-\mathrm{T}-$ ). The mean ITI was $150 \mathrm{sec}$. This test was repeated 3 days later.

Facilitation and inhibition retraining. The mice were retrained on the concurrent facilitation and inhibition problems for 9 days. Details of these retraining sessions were the same as those for the original training.

Target reversal and transfer testing. In order to improve our ability to detect transfer of facilitation and inhibition, the levels of responding to the auditory targets were then adjusted through differential conditioning. All the subjects received three sessions in which the target trained in the facilitation procedure was reinforced and the target trained in the inhibition procedure was nonreinforced. In each of these three sessions, there were eight presentations of each target for $5 \mathrm{sec}$ with a mean ITI of $150 \mathrm{sec}$. The order of trials was randomized. The subjects then received an additional session with eight presentations of each target, all of which were nonreinforced, followed a day later by a transfer test that was identical in format to the previous transfer tests.

\section{Results and Discussion}

\section{Facilitation and Inhibition Training}

Figure 7 plots the development of facilitation and inhibition. Differential responding was acquired in accordance with the reinforcement contingencies. Thus, as facilitation training progressed, responding increased substantially to the auditory target in the presence of the facilitator (FacTar+) and, after an initial increase to that target alone (Tar-), declined to a low rate similar to that observed in our previous experiments. Conversely, as inhibition training progressed, responding increased initially to the auditory target in the presence of the inhibitor (InhTar-) but then declined systematically to a level slightly higher than that to Tar-. Responding to that target alone (Tar+) increased over the course of training but remained at a level slightly below that to FacTar+. Statistical analyses of the terminal session of facilitation and inhibition training revealed significant differences between responding to an auditory target alone and in the presence of its facilitator $[F(1,31)=79.92, p<.01]$ and between responding to an auditory target alone and in the presence of its inhibitor $[F(1,31)=68.47, p<.01]$.

\section{Transfer Test}

The data from the transfer test are summarized in Figure 8: Responding to the auditory target used for facilitation training (facilitation target) is shown in Figure 8A, and responding to the auditory target used for inhibition training (inhibition target) is shown in Figure 8B. For each target, the mean response rate is shown to the target alone (Tar- and Tar+), during presentation of the facilitator (FacTar+ and Fac), and during presentation of the inhibitor (Inh and InhTar-). For both facilitation and inhibition, the original discriminations were preserved. Thus, responding to a target increased significantly in the presence of its facilitator [FacTar $+; F(1,31)=42.65, p<.01]$ and decreased significantly in the presence of its inhibitor $[$ InhTar-; $F(1,31)=49.67, p<.01]$. Of more interest are the results of the transfer trials. When the inhibitor was presented with the target used for facilitation training (Inh), responding to the target significantly decreased 


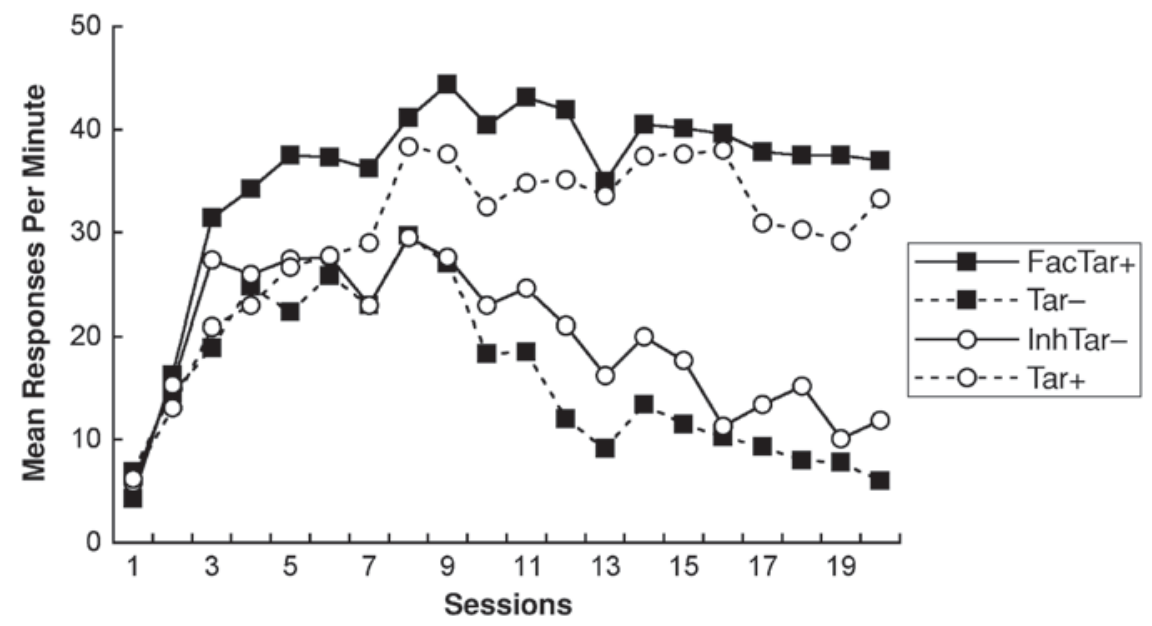

Figure 7. Experiment 4: acquisition of facilitation and inhibition. Shown are the mean rates of head entries into the food magazine for one auditory target presented alone and nonreinforced (Tar-) or with a light facilitator and reinforced (FacTar + ) and for a different auditory target presented alone and reinforced (Tar+) or with a light inhibitor and nonreinforced (InhTar-).

$[F(1,31)=7.25, p=.01]$. In contrast, when the facilitator was presented with the target used for inhibition training (Fac), responding to the target showed a nonsignificant increase $[F(1,31)=1.39, p>.10]$.

This pattern of results is important for two reasons. First, it demonstrates that the mice clearly discriminated between the two visual cues and that it was the conditioned status of those cues that controlled their effect on responding to the auditory targets. If the animals had been unable to discriminate between the lights, there would have been no difference between responding to a target in the presence of its trained stimulus and in the presence of the transfer stimulus. Second, the successful transfer of the inhibitor across targets is consistent with a modulatory account of inhibition. However, the results regarding transfer of facilitation are inconclusive. The failure to observe significant transfer of facilitation may have been the result of a ceiling effect due to the already high level of responding to the target alone. This interpretation was supported by subsequent testing.
A

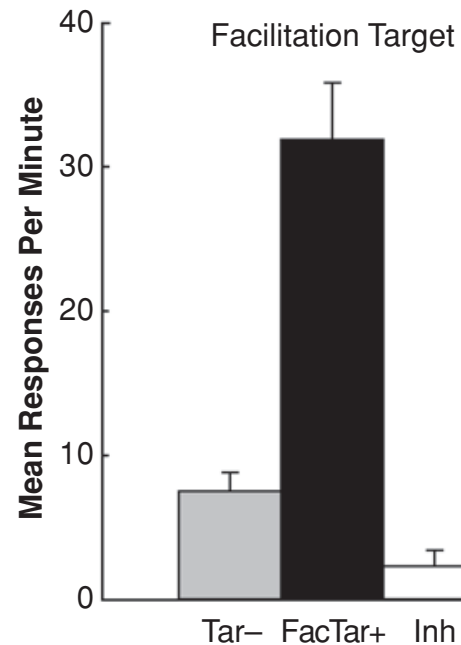

B

Inhibition Target

Figure 8. Experiment 4: mean responses per minute during the transfer test. Panel A shows responding to the target that was used for facilitation training when it was presented alone (Tar-), with its facilitator (FacTar +$)$, or with the inhibitor (Inh). Panel B shows responding to the target that was used for conditioned inhibition training when it was presented alone (Tar +$)$, with its inhibitor (InhTar-), or with the facilitator (Fac). All the test trials were nonreinforced. 


\section{Facilitation and Inhibition Retraining}

Retraining of the facilitation and inhibition discriminations proceeded smoothly. The mean rate of responding to the target with its facilitator was 37.7 responses per minute, which was significantly higher than responding to the target alone at 7.7 responses per minute $[F(1,30)=$ $53.41, p<.01]$. The mean rate of responding to the target with its inhibitor was 7.1 responses per minute, which was significantly lower than responding to the target alone at 28.7 responses per minute $[F(1,30)=75.27, p<.01]$.

\section{Extinction and Testing}

Over the course of extinction training, responding to the facilitator decreased from a low level of 8.7 responses per minute in Session 1 to under 2 responses per minute for the last three sessions of extinction. Responding to the inhibitor was consistently low across the six sessions of extinction and never exceeded 2 responses per minute. In the final session of extinction, the mean response rate was 1.5 responses per minute to the facilitator and 0.7 responses per minute to the inhibitor.

The data of most interest come from the postextinction transfer test, in which the effect of nonreinforced presentations of the facilitator or the inhibitor on its ability to modulate responding to the auditory targets was assessed. Figures 9A and 9B show the data for the subjects given nonreinforced presentations of the facilitator, and Figures 9C and 9D show the data for the subjects given nonreinforced presentations of the inhibitor. There are four points to note. First, nonreinforced presentations of
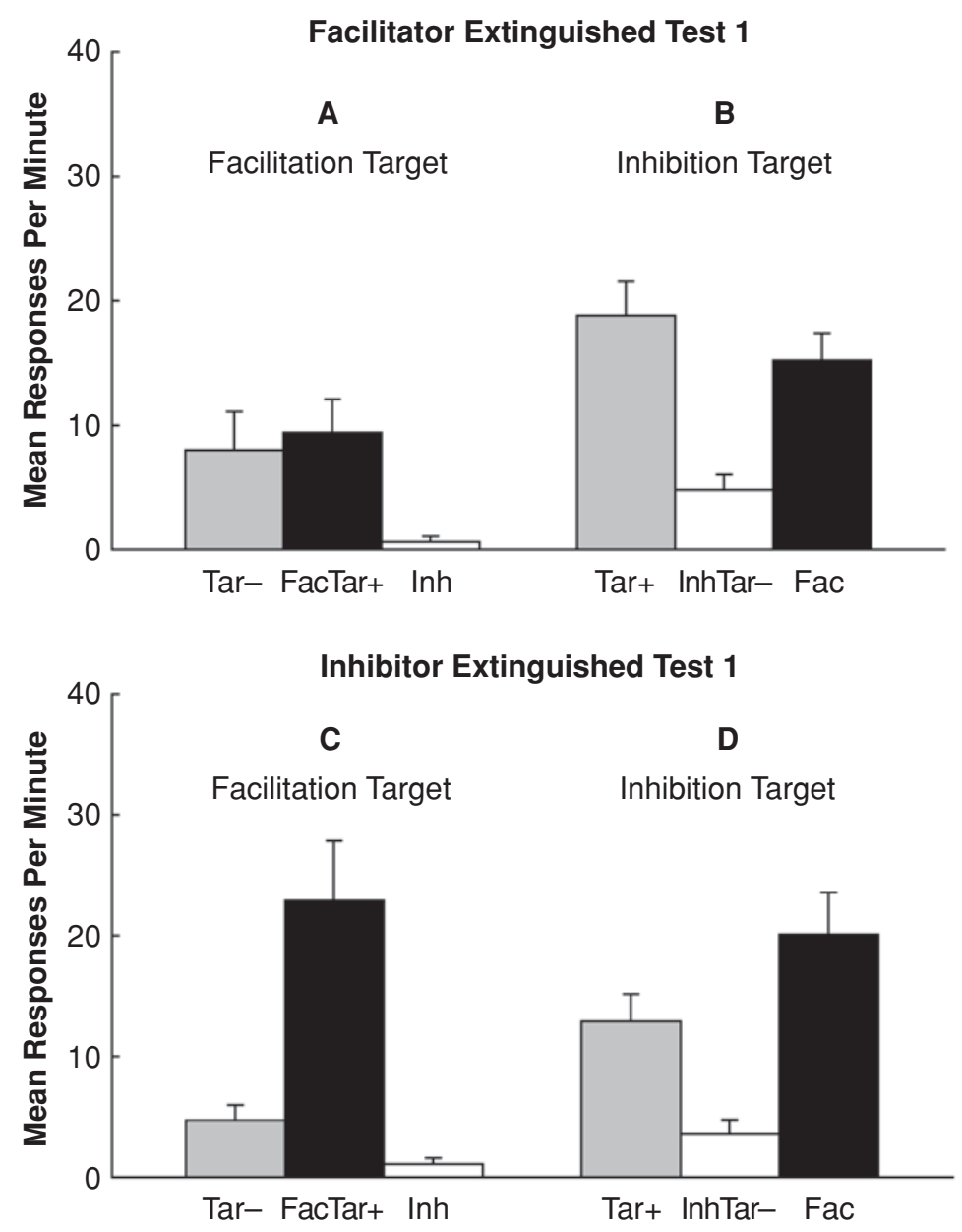

Figure 9. Experiment 4: mean responses per minute during the postextinction transfer test. Panels $A$ and $B$ show responding when the facilitator was extinguished, and Panels $C$ and $D$ show responding when the inhibitor was extinguished. Panels $\mathrm{A}$ and $\mathrm{C}$ show responding to the target that was used for facilitation training when it was presented alone (Tar-), with its facilitator (FacTar+), or with the inhibitor (Inh); Panels B and D show responding to the target that was used for conditioned inhibition training when it was presented alone (Tar+), with its inhibitor (InhTar-), or with the facilitator (Fac). All the test trials were nonreinforced. 
the facilitator eliminated its ability to promote responding to its target. There was no significant difference between responding to the target alone and responding to the target in the presence of the extinguished facilitator $(F<1)$; however, facilitation was preserved in the animals that received extinction treatment with the inhibitor $[F(1,15)=$ $13.35, p<.01]$. Second, nonreinforced presentations of the inhibitor did not affect its ability to reduce responding to its target. Responding to the target was significantly reduced in the presence of the inhibitor with which it had been trained, regardless of whether that inhibitor had undergone extinction $[F(1,15)=37.95, p<.01]$ or not $[F(1,14)=19.94, p<.01]$. Third, transfer of facilitation was observed in the animals that received extinction treatment with the inhibitor. In those animals, the untreated facilitator significantly promoted responding to the target used for inhibitory training $[F(1,15)=5.1, p<.05]$. Not surprisingly, transfer of facilitation was not observed with the extinguished facilitator $[F(1,14)=2.15, p>.10]$. The final point to note is that transfer of inhibition was obtained with both the extinguished and the untreated inhibitors. Responding to the target used for facilitation training was reduced by the inhibitor regardless of whether or not it had been presented alone and nonreinforced $[F(1,15)=$ $5.6, p<.05$, for the extinguished inhibitor; $F(1,14)=6.4$, $p<.05$, for the untreated inhibitor]. This pattern of results was replicated in the second test given 3 days later.

\section{Facilitation and Inhibition Retraining}

By the end of facilitation and inhibition retraining, performance on both discriminations had been restored to preextinction levels. In the final retraining session, the mean rates of responding to the target alone and to the target in the presence of the facilitator were 6.9 and 30.8 responses per minute, respectively, for the subjects that had received extinction of the inhibitor and 8.5 and 34.9 responses per minute, respectively, for the subjects that had received extinction of the facilitator. A statistical analysis of the data showed no significant effect of group $(F<1)$ and no significant group $\times$ trial type interaction $(F<1)$, but the difference between responding to the target alone and in the presence of the facilitator was significant $[F(1,29)=58.2, p<.01]$. The mean rates of responding to the target alone and to the target in the presence of the inhibitor in the final retraining session were 28.8 and 5.3 responses per minute, respectively, for the subjects that had received extinction of the inhibitor and 28.8 and 6.4 responses per minute, respectively, for the subjects that had received extinction of the facilitator. A statistical analysis of the data showed no significant effect of group $(F<1)$ and no significant group $\times$ trial type interaction $(F<1)$, but the difference between responding to the target alone and in the presence of the inhibitor was significant $[F(1,29)=103.4, p<.01]$.

\section{Target Reversal and Transfer Testing}

The results of the transfer test are shown in Figure 10. Responding to the auditory target used for facilitation training (facilitation target) is shown in Figure 10A, and responding to the auditory target used for inhibition training (inhibition target) is shown in Figure 10B. For each target (facilitated and inhibited), the mean response rate is shown to the target alone (Tar- and $\mathrm{Tar}+$ ), during presentation of the facilitator (FacTar+ and Fac), and during presentation of the inhibitor (Inh and InhTar-). Differential treatment of the targets had the desired effect of reducing responding to the inhibition target and increasing responding to the facilitation target. As a result, there was strong evidence for both transfer of facilitation and inhibition. When the inhibitor was presented with the target used for

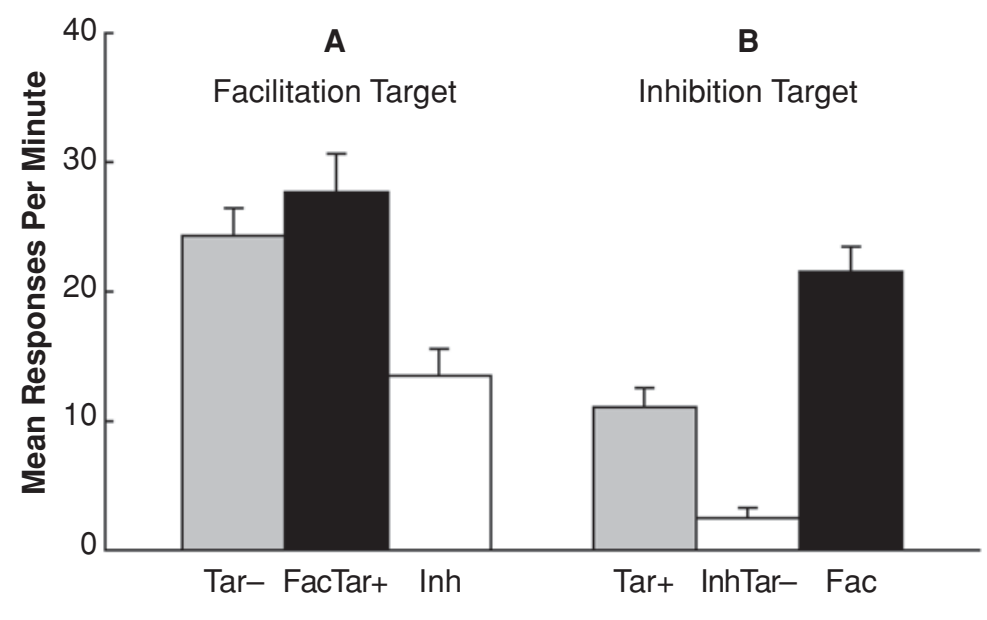

Figure 10. Experiment 4: mean responses per minute during the second transfer test. Panel A shows responding to the target that was used for facilitation training when it was presented alone (Tar-), with its facilitator (FacTar + ), or with the inhibitor (Inh). Panel B shows responding to the target that was used for conditioned inhibition training when it was presented alone (Tar + ), with its inhibitor (InhTar-), or with the facilitator (Fac). All the test trials were nonreinforced. 
facilitation training (Inh), responding to the target significantly decreased $[F(1,30)=25.95, p<.01]$. In contrast, when the facilitator was presented with the target used for inhibition training $(\mathrm{Fac})$, responding to the target showed a significant increase $[F(1,30)=30.29, p<.01]$. Although this change in the level of responding to the targets alone improved detection of transfer, it interfered partially with the original discriminations. Thus, although responding to a target increased in the presence of its facilitator (FacTar + ), that increase was no longer significant $[F(1,30)=$ $2.02, p>.10]$. However, responding continued to show a significant decrease in the presence of its inhibitor $[$ InhTar $-; F(1,30)=30.15, p<.01]$.

In summary, Experiment 4 provided strong confirmation of our previous findings that facilitation is extinguished in the mouse by nonreinforced presentations of the facilitator. It also yielded two novel results. First, this experiment demonstrated that facilitation does transfer across targets in mice, a finding that is in line with related work with rats and pigeons. Second, it offered support for a modulatory account of CI performance. Experiment 4 showed that an inhibitor will transfer across targets and that it is resistant to the potential decremental effects of nonreinforcement, again confirming work with rats and pigeons. With the exception of the decremental effect of nonreinforced presentations of the facilitator, the general pattern of results provides preferentially strong support for Rescorla's (1985) US threshold modulation account of facilitation and inhibition.

\section{EXPERIMENT 5}

The aim of Experiment 5 was to examine acquisition of a biconditional discrimination in which two stimulus combinations (AX and BY) were reinforced and two related stimulus combinations ( $\mathrm{AY}$ and $\mathrm{BX}$ ) were not. This discrimination can be viewed as combining the facilitation and inhibition procedures used in Experiment 4 so that a single stimulus signals when one target is reinforced with food and when another target is nonreinforced. The ability of animals to solve discriminations of this type has been of theoretical interest because of the implications of differential responding for various models of discrimination learning (e.g., Colwill \& Delamater, 1995; Holland, 1991; Honey \& Watt, 1998; Nakajima, 1998; Pearce, 1987, 1994). In particular, there is general agreement that biconditional discriminative performance cannot be explained merely by attributing to A and B the power to modulate the threshold for activation of the US representation (e.g., Holland, 1991; Holland \& Reeve, 1991; Nakajima, 1998). In large part, this prediction follows from the fact that a single stimulus cannot concurrently shift that threshold in opposite directions. Indeed, it is this constraint that underlies the explanation for why training a facilitator as an inhibitor is an effective treatment for extinction of facilitation and for why training an inhibitor as a facilitator is an effective treatment for extinction of inhibition.
Explanations for successful biconditional discrimination performance have invoked both modulatory (e.g., Holland, 1983) and nonmodulatory (e.g., Pearce, 1987, 1994) solutions. According to Holland's $(1983,1985)$ specific occasion-setting account, A would operate positively on the $\mathrm{X}$-US association and negatively on the Y-US association, whereas B would do the opposite. This modulatory approach is typically contrasted with the nonmodulatory approach taken by Pearce. Adopting the view that compound stimuli are represented as configurations, Pearce has argued that a biconditional discrimination reduces to a simple Pavlovian discrimination between two configural cues (AX and BY) that are reinforced and two configural cues (AY and BX) that are not reinforced.

A number of studies have shown successful performance on Pavlovian and instrumental biconditional discriminations in several species, including bees (Schubert, Lachnit, Francucci, \& Giurfa, 2002), rabbits (Saavedra, 1975), rats (Colwill \& Delamater, 1995; Honey \& Watt, 1999; Preston, Dickinson, \& Mackintosh, 1986; Trapold, 1970), and pigeons (Looney, Cohen, Brady, \& Cohen, 1977; Thomas \& Goldberg, 1985). To our knowledge, however, there have been no studies of biconditional discrimination learning in the mouse. Experiment 5 addressed this omission, with the objective of examining the implications of successful biconditional discrimination performance for the analysis of facilitation in the mouse. C57BL/6J mice were trained on a biconditional discrimination in which one auditory target (A1) was reinforced in the presence of one visual stimulus (L1), but not in the presence of another (L2), and a different auditory target (A2) was reinforced in the presence of L2, but not in the presence of L1. Each light was presented for $15 \mathrm{sec}$, and the auditory targets occurred during the last $5 \mathrm{sec}$ of the light. The question of interest was whether responding to an auditory target would be higher in the presence of the light when it was followed by food.

Interestingly, despite extensive training on the biconditional task, discriminative responding did not develop: Responding was as high to the reinforced targets $(\mathrm{L} 1-\mathrm{A} 1+$ and $\mathrm{L} 2-\mathrm{A} 2+)$ as it was to the nonreinforced targets $(\mathrm{L} 1-\mathrm{A} 2-$ and $\mathrm{L} 2-\mathrm{A} 1-)$. To explore the source of this failure to respond differentially as a function of the reinforcement contingencies, two series of tests were run. First, a series of serial test trials was conducted in which L1 and L2 preceded but did not overlap with A1 and A2. This allowed assessment of responding to the auditory targets in the absence of a direct response to the lights. It also approximated a procedure used by Honey and Watt (1998) to examine biconditional discrimination learning in rats. Second, a savings test was used in which one of the auditory targets was reinforced during one light, but not during the other light. This arrangement was either consistent with the previous reinforcement contingencies $(\mathrm{L} 1-\mathrm{A} 1+, \mathrm{L} 2-\mathrm{A} 1-)$ or inconsistent $(\mathrm{L} 1-\mathrm{A} 1-$, $\mathrm{L} 2-\mathrm{A} 1+)$. The question of interest was whether acquisition by the consistent group would be superior to that by 
the inconsistent group, which would indicate that some specific learning had occurred despite the indiscriminate pattern of responding.

Method
Subjects and Apparatus
Sixteen experimentally naive male C57BL/6J mice (Jackson
Labs), approximately 50 days old at the start of the experiment,
served as subjects. The conditions for housing and maintenance
were the same as those in Experiment 1 . The apparatus was the same
as that used in Experiment 3A.

\section{Procedure}

Magazine training. The subjects were given one session of magazine training, in which 15 food pellets were delivered on a VT 60 -sec schedule.

Biconditional discrimination training. Each session of biconditional discrimination training consisted of eight 5-sec presentations of each auditory target, noise $(\mathrm{N})$ and tone $(\mathrm{T})$, with a mean ITI of $150 \mathrm{sec}$. Four presentations of each auditory stimulus were embedded in the last $5 \mathrm{sec}$ of a 15 -sec houselight (L1), and the other four presentations of each auditory stimulus were embedded in the last $5 \mathrm{sec}$ of a 15 -sec panel light (L2). One auditory stimulus was reinforced in the presence of $\mathrm{L} 1$ and nonreinforced in the presence of L2; the other auditory stimulus was reinforced in the presence of L2, but not in the presence of L1. For half the animals, N was reinforced in $\mathrm{L} 1$, but not in $\mathrm{L} 2$, and $\mathrm{T}$ was reinforced in $\mathrm{L} 2$, but not in $\mathrm{L} 1(\mathrm{~L} 1-\mathrm{N}+, \mathrm{L} 1-\mathrm{T}-, \mathrm{L} 2-\mathrm{N}-, \mathrm{L} 2-\mathrm{T}+)$. These contingencies were switched for the remaining animals $(\mathrm{L} 1-\mathrm{N}-, \mathrm{L} 1-\mathrm{T}+$, $\mathrm{L} 2-\mathrm{N}+, \mathrm{L} 2-\mathrm{T}-$ ). On reinforced trials, a single food pellet was delivered coincident with stimulus offset. An equal number of each of the four trial types occurred in the first half of each session, with the order randomized across days. The order of trials in the second half of each session was a mirror image of the order in the first half of that session.

To examine the possibility that the subjects had learned the biconditional discrimination but were impaired in their capacity to express that knowledge, two series of tests were run. The first series involved 21 sessions of serial testing of the biconditional discrimination. Each of these sessions was identical to those used for the original training, except that the targets were presented at the end of the 15 -sec light stimuli (not in the last $5 \mathrm{sec}$ of the light stimuli). In this way, responding to the auditory targets could be observed in the absence of any response to the visual cues.

In the second series of tests, the mice were given training on a subset of the light-target relations used in the original biconditional discrimination. All the animals received 28 sessions in which the noise target was reinforced in the presence of one light, but not in the presence of the other light (e.g., $\mathrm{L} 1-\mathrm{N}+$ and $\mathrm{L} 2-\mathrm{N}-$ ). For half the subjects, this arrangement was consistent with their original training, and for the other 8 subjects, this arrangement was inconsistent with their original training. Each session contained 12 trials of each type. On each trial, a light was presented for $15 \mathrm{sec}$, with the noise co-occurring in the last $5 \mathrm{sec}$.

\section{Results and Discussion}

\section{Biconditional Discrimination Training}

Figure 11A displays responding in blocks of 4 sessions to the auditory targets in the presence of the lights for each of the two reinforced compounds and for each of the two nonreinforced compounds during initial biconditional training. After a steep rise in the rate of responding to the auditory targets at the start of training, responding remained high throughout training to both reinforced and nonreinforced compounds. At the end of 80 training sessions, there was still no evidence of any discrimination between the visual-auditory compounds based on the differential reinforcement contingencies. The rate of responding was slightly higher on trials with the noise target than on those with the tone target. In the final training session, the mean rates of responding on the nonreinforced trials were 25.3 responses per minute to the noise target $(\mathrm{L} 2-\mathrm{N}-$ or $\mathrm{L} 1-\mathrm{N}-)$ and 22.9 responses per minute to the tone target $(\mathrm{L} 1-\mathrm{T}-$ or $\mathrm{L} 2-\mathrm{T}-)$; the mean rates of responding on the reinforced trials were 27.2 responses per minute to the noise target $(\mathrm{L} 1-\mathrm{N}+$ or $\mathrm{L} 2-\mathrm{N}+)$ and 22.7 responses per minute to the tone target $(\mathrm{L} 2-\mathrm{T}+$ or $\mathrm{L} 1-\mathrm{T}+)$. A repeated measures ANOVA showed no significant effect of target identity $[F(1,15)=3.28, p>.05]$

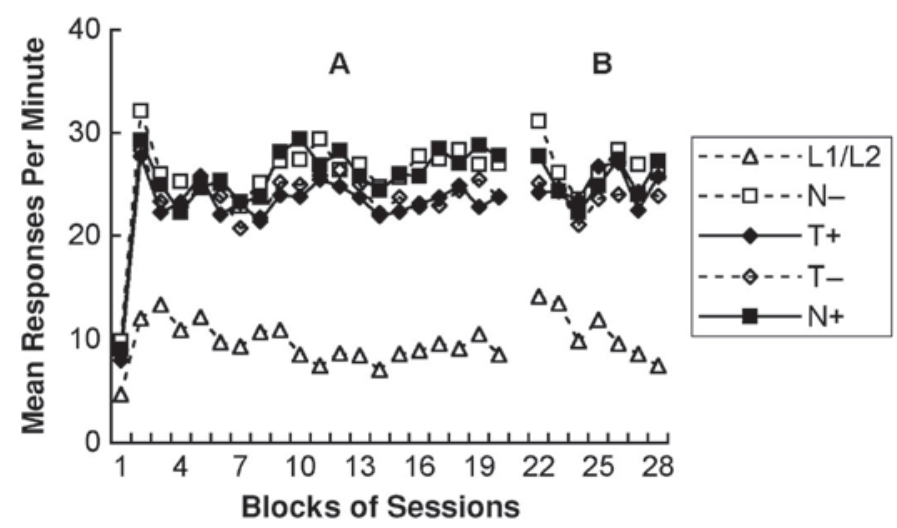

Figure 11. Experiment 5: biconditional discrimination performance. Panel A shows the mean rates of head entries into the food magazine during initial acquisition, plotted in blocks of four sessions. Panel B shows the mean response rates during serial testing in blocks of three sessions. In both phases, responding is shown to the 5 -sec noise $(\mathrm{N})$ and tone $(\mathrm{T})$ targets and to the lights alone (L1/L2). A "+" indicates reinforced, and a "-" indicates nonreinforced. 
or of reinforcement $(F<1)$ and no significant interaction of these factors $(F<1)$.

Figure 11B displays the results of serial testing in blocks of three sessions. The first point to note is that, with the exception of a slight increase in responding to the nonreinforced noise, responding to the auditory targets was essentially unperturbed by the shift to a serial presentation procedure. The second point to note is that differential responding did not emerge over the course of serial testing. In the final session of serial testing, the mean rates of responding on the nonreinforced trials were 26.6 responses per minute to the noise target and 22.3 responses per minute to the tone target; on reinforced trials, the mean rates of responding were 26.4 responses per minute to the noise target and 24.9 responses per minute to the tone target. A repeated measures ANOVA showed no significant effect of target identity $[F(1,15)=2.17, p>$ $.10]$ or of reinforcement $[F(1,15)=1.64, p>.10]$ and no significant interaction of these factors $(F<1)$. On the basis of these data, it seems unlikely that the lights were eliciting a response that obscured differential responding to the reinforced and nonreinforced auditory targets. Instead, these data suggest an insensitivity to the differential reinforcement contingencies operating in a biconditional discrimination.

The results of the savings test, shown in Figure 12, support the view that the mice in this experiment were insensitive to the differential reinforcement contingencies in the biconditional discrimination. Both the consistent and the inconsistent groups acquired the simplified version of the biconditional discrimination, as indexed by their higher rate of responding to the noise target in the presence of the light that signaled its reinforcement than in the presence of the light that signaled its nonreinforcement. Although the data plotted in Figure 12 give the impression that this conditional discrimination developed more quickly and to a superior degree in the consistent group, a mixed factors ANOVA revealed no statistical support for that impression. There was no significant main effect of group $(F<1)$ and no significant interactions of that factor with sessions $(F<1)$ or reinforcement $[F(1,14)=$ $1.6, p>.10]$ or with their interaction $[F(27,378)=1.15$, $p>.10]$. There was, however, a significant sessions $\times$ reinforcement interaction $[F(27,378)=15.57, p<.01]$, which is consistent with the pattern of data presented in Figure 12 showing that as training progressed, responding remained high on $\mathrm{L} 1-\mathrm{N}+$ trials but decreased substantially on $\mathrm{L} 2-\mathrm{N}-$ trials.

Experiment 5 offers no evidence that C57BL/6J mice can acquire differential responding on a biconditional discrimination. Differential responding was not obtained after 80 sessions of training and did not appear during 21 sessions of serial testing. Moreover, there was no statistically significant difference in the development of differential responding on a simple conditional discrimination as a function of whether the reinforcement contingencies were the same as those in original biconditional discrimination training or were switched. Although the biconditional discrimination is reputed to be a difficult task when the same reinforcing outcome is used, other studies have obtained evidence that it can be acquired in other species with parameter values similar, although not identical, to those employed here. For example, Honey and Watt (1998) found that rats readily developed differential responding to presentations of $\mathrm{X}$ and $\mathrm{Y}$ when their pairing with food was signaled by A and B or C and D, respectively, and their nonreinforcement was signaled by $\mathrm{C}$ and $\mathrm{D}$ or $\mathrm{A}$ and $\mathrm{B}$, respectively. In that study, $\mathrm{X}$ and $\mathrm{Y}$ were 10 -sec visual cues, and A, B, C, and D were 10 -sec auditory cues. Each session contained five presentations of each of the eight trial types, with a mean ITI of $120 \mathrm{sec}$. A statistical analysis of responding across six blocks of 8

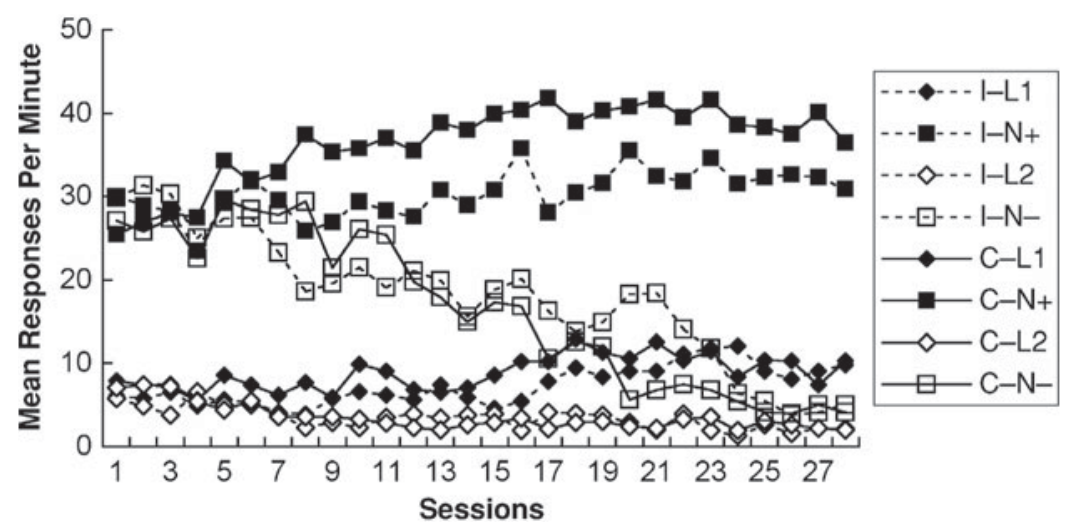

Figure 12. Experiment 5: savings test. Mean rates of head entries into the food magazine are shown for a 5-sec noise target when it was reinforced $(\mathrm{N}+)$ or not reinforced $(\mathrm{N}-)$. On reinforced trials, $N$ was presented in the last 5 sec of a 15-sec light (L1), and on nonreinforced trials, $N$ was presented in the last 5 sec of a different 15-sec light (L2). Head entries in the first $10 \mathrm{sec}$ of $\mathrm{L1}$ and $\mathrm{L} 2$ are plotted separately. For Group Consistent ( $\mathrm{C}$, solid lines), the reinforcement contingencies for these compounds were the same as those in biconditional discrimination training; for Group Inconsistent (I, dashed lines), the reinforcement contingencies were switched. 
sessions each revealed significantly more responses on reinforced than on nonreinforced trials in all but the first block. Despite the problems inherent in making comparisons across species, it does seem unlikely that the amount of training provided in Experiment 5 was insufficient to produce differential responding.

On the other hand, there is evidence that the rate of acquisition of differential responding on a biconditional discrimination can be influenced by specific training parameters. It will be important to determine whether the C57BL/6J mouse can show differential responding on a biconditional discrimination under any circumstances. An appropriate starting point for addressing this issue might be to manipulate three variables that have been identified in other studies as affecting acquisition of a biconditional discrimination. Honey and Watt (1999) found acquisition of differential responding with contextual cues that signaled the reinforcement and nonreinforcement of $\mathrm{X}$ and $\mathrm{Y}$ to be faster than that in an earlier experiment in which discrete cues were used (Honey \& Watt, 1998). Thomas and Goldberg (1985) found better discriminative performance in pigeons with a daily alternation procedure in which reinforced trials with one target and nonreinforced trials with the other target (e.g., $\mathrm{A}-\mathrm{X}+$ and $\mathrm{A}-\mathrm{Y}-$ ) occurred on one day and the reverse reinforcement contingencies (e.g., $\mathrm{B}-\mathrm{X}-$ and $\mathrm{B}-\mathrm{Y}+$ ) operated on a different day than with the conventional training schedule in which all trial types are mixed within a session. Finally, Trapold (1970) obtained superior discriminative performance on an instrumental biconditional discrimination when one food outcome was used for reinforcing one response and a different food outcome was used to reinforce the other response.

Quite aside from the problem of determining whether C57BL/6J mice can demonstrate biconditional discrimination learning under any circumstances is the question of why they failed to solve the problem in the present experiment. The US threshold modulation account provides a straightforward explanation for the lack of differential responding in terms of transfer. L1 and L2 each promoted responding to their own reinforced targets, but that facilitation transferred to the other's reinforced target. According to this model, using different outcomes for the two reinforced combinations would yield differential performance, because transfer is specific to the US. In contrast, both the specific occasion-setting model (Holland, 1983, 1985) and the configural cue account (Pearce, 1987, 1994) attribute the lack of differential responding to a discrimination failure. As a result, the different compounds would have been indistinguishable from a single compound receiving partial reinforcement. Decreasing the similarity of the stimulus combinations would be expected to increase the emergence of differential responding. This could likely be achieved either by using different outcomes or by using contextual cues with discrete targets.

\section{GENERAL DISCUSSION}

This article has presented the results of a series of experiments designed to examine acquisition and extinction of facilitation in the C57BL/6J mouse. Responding to an auditory target that was reinforced only in conjunction with a visual facilitator was enhanced in the presence of that facilitator. Experiments 1 and $3 \mathrm{~B}$ showed that this enhancement effect was reversed by $\mathrm{CI}$ training in which the facilitator was established as a signal for the nonreinforcement of another stimulus that was otherwise followed by food. This enhancement effect was also reduced by nonreinforced presentations of the facilitator either in a discrimination procedure (Experiment 1) or alone (Experiments 2, 3A, and 4). These effects were obtained with both the conventional feature-positive procedure (Experiments 3A, 3B, and 4) and the positive patterning procedure (Experiments 1 and 2). Two additional findings reported in Experiment 4 included a demonstration of transfer of both facilitation and inhibition across targets and a demonstration that nonreinforced presentations of an inhibitor do not impair its ability to suppress responding. Finally, Experiment 5 showed no evidence for differential responding on a biconditional discrimination task.

For the most part, these findings favor a general modulatory analysis of facilitation, rather than the class of specific modulatory models. In particular, the observation of transfer of both facilitation and inhibition and the elimination of facilitation by CI training provide preferential support for the US threshold modulation approach. Indeed, even the failure to obtain differential responding on the biconditional discrimination in Experiment 5 supports this approach. In fact, the only discrepancy between the present results and the US threshold modulatory account (Rescorla, 1985) is our finding that simple nonreinforcement of the facilitator was effective in reducing its ability to enhance responding to an auditory target. That finding is, of course, also contrary to the predictions of the specific modulatory models, and it is at odds with the empirical results of Rescorla (1986a) with pigeons and of Holland (1989b) with rats.

However, there are two ways in which we might be able to reconcile the attenuation of facilitation by simple extinction with the US threshold modulatory account. One potential explanation is based on the premise that the context in which the facilitator is nonreinforced is excitatory. The nonreinforcement of this background stimulus in the presence of the facilitator thus satisfies the critical condition for extinction of facilitation identified by Rescorla (1986a). Consistent with this proposition is the fact that for Group C in Experiment 2, the rate of magazine entries on pseudotrials showed a modest decline across extinction sessions. Also consistent with this proposal is the more drastic outcome of Experiment 1, in which facilitation was abolished, relative to Experiment $3 \mathrm{~A}$, in which facilitation was preserved but attenuated following nonreinforced presentations of the facilitator. More direct evidence to support this analysis would involve demonstrating that extinction of the context prior to nonreinforced presentations of the facilitator alone preserves the ability of that facilitator to enhance responding to its target.

An alternative way of reconciling our finding that facilitation was reduced by simple extinction of the facilitator is 
to assert that a salient feature of the facilitator that modulates responding to the auditory target is its own excitatory strength (Swartzentruber, 1998). There is evidence from studies with pigeons that the expectation of a US elicited by a discriminative stimulus may sometimes overshadow the physical properties of that stimulus and gain preferential control over responding (Urcuioli, 1984, 1985, 1990). It is worth noting that, in keeping with this explanation, there was a slight decline in the rate of responding to the facilitator during its nonreinforced presentations in all of the experiments reported here. Of course that decline might reflect extinction of a facilitator-target association, rather than a facilitator-US association. A fairly direct way to evaluate the idea that the key feature of a facilitator is its own excitation would be to examine, in the mouse, whether a simple Pavlovian excitor would substitute for the facilitator in promoting responding to the target.

Whichever of these two approaches one favors for accommodating the present results within a modulatory framework, the question of why there is a discrepancy between the data from the mouse and the data from rats and pigeons concerning the effects of nonreinforced presentations of a facilitator will still need to be addressed. A prudent start would be to examine the possibility that the discrepancy arises from a difference in the parameter values used for simple extinction of the facilitator in the various studies. For instance, in the present experiments, there were fewer nonreinforced presentations of the facilitator per session, and they were more widely spaced, with a mean ITI of $150 \mathrm{sec}$, than in Rescorla's (1986a) study, in which a more concentrated exposure with a mean ITI of $60 \mathrm{sec}$ was used. Other studies have shown that the acquisition of Pavlovian conditioning may be improved with longer ITIs (Frey \& Ross, 1968; Gibbon, Baldock, Locurto, Gold, \& Terrace, 1977; Kehoe \& Gormezano, 1974) and fewer trials per day (Kehoe \& Gormezano, 1974). Similar benefits of trial spacing have been documented for the acquisition of serial feature-positive discriminations (Holland, 1995, 1999). The possibility should not be discounted that a similar beneficial effect may occur for extinction and that, with parameters more similar to those used in the present experiments, Rescorla (1986a) and Holland (1989b) might have obtained a reduced enhancement effect.

Modulatory accounts for relational discrimination learning, however, have not gone unchallenged, and it is important to at least consider the present results in the light of nonmodulatory models of occasion setting and related discriminations. According to Pearce's $(1987,1994)$ configural cue account of facilitation, the individual elements are assumed to become relatively neutral, whereas a direct excitatory Pavlovian association develops between the configuration of those elements and the US representation. Using stimuli from different sensory modalities, as we did in the present experiments, is thought to discourage such configural conditioning (Holland, 1983, 1989a; Lamarre \& Holland, 1987). Moreover, the results of Experiment 5 detailing indiscriminate responding on the biconditional task make it less likely that a configural cue strategy was used to solve the facilitation procedure in the present experiments. Finally, it is relevant to note that this account does not offer a straightforward explanation for the decremental effect of postacquisition nonreinforced presentations of the facilitator, particularly when such presentations are scheduled during discrimination acquisition, as they were in Experiments 1 and 2.

The other possibility relies on a simple elemental analysis of conditioning. In a problem in which a compound stimulus is reinforced $(\mathrm{XA}+)$ and one of the elements of the compound is nonreinforced (A-), X may just develop a simple excitatory association with the US (Hearst, 1978). An attractive feature of this account is that it readily anticipates a detrimental effect on performance of postacquisition nonreinforced presentations of $\mathrm{X}$. On the basis of extensive work by Holland and his colleagues (Holland, 1986, 1992; Ross \& Holland, 1981), it is clear that the temporal arrangement between $\mathrm{X}$ and $\mathrm{A}$ can have a strong influence on the nature of the associations formed. In the experiments reported here, a temporal asynchrony was arranged between the onsets of $\mathrm{X}$ and $\mathrm{A}$ that would favor a solution in which X modulates the response to $\mathrm{A}$. In addition, the inclusion of nonreinforced presentations of $\mathrm{X}$ in Experiments 1 and 2 further discouraged the use of a direct Pavlovian association between X and the US.

The main reason to think that such a strategy was not used here is that the response elicited in the presence of the facilitator-target compound was appropriate to the target, not to the facilitator. In the present experiments, high rates of magazine entries with the auditory target in the presence of the light facilitator were observed, indicating that the light was modulating the response to the auditory target. Determining whether the conditioned response to a light paired with food is qualitatively different from that elicited by an auditory CS paired with food would, of course, enable us to strengthen that conclusion. In addition, it would provide a powerful tool for further analysis of discrimination learning in the mouse (e.g., Holland, 1986; Holland \& Ross, 1981), and it could potentially allay concerns about the source of responding that was obtained with the light facilitators in these experiments. For now, it is encouraging that the facilitation acquisition data we have obtained with the mouse are similar to those that have been obtained with rats and parallel to those obtained with pigeons.

An important goal of future studies will be to examine further the mechanisms involved in occasion setting and related discriminations in the mouse. Such information will be valuable for conditioning experiments in general, as attempts are made to meet the increasing demand for learning and memory procedures amenable to a genetic analysis of behavioral plasticity. And it is in the context of meeting that need that the present experiments should be primarily appreciated, since they provide the first investigation of facilitation in the mouse. 


\section{REFERENCES}

Brandon, S. E., \& Wagner, A. R. (1991). Modulation of a discrete Pavlovian conditioned reflex by a putative emotive Pavlovian conditioned stimulus. Journal of Experimental Psychology: Animal Behavior Processes, 17, 299-311.

Brandon, S. E., \& Wagner, A. R. (1998). Occasion setting: Influences of conditioned emotional responses and configural cues. In N. A. Schmajuk \& P. C. Holland (Eds.), Occasion setting: Associative learning and cognition in animals (pp. 343-382). Washington, DC: American Psychological Association.

Colwill, R. M., \& Delamater, B. A. (1995). An associative analysis of instrumental biconditional discrimination learning. Animal Learning \& Behavior, 23, 218-233.

DAVIDSON, T. L., \& RESCORLA, R. A. (1986). Transfer of facilitation in the rat. Animal Learning \& Behavior, 14, 380-386.

Frey, P. W., \& Ross, L. E. (1968). Rabbit eyelid conditioning: Effects of age, interstimulus interval, and intertrial interval. Developmental Psychobiology, 1, 276-279.

Gibbon, J., Baldock, M. D., Locurto, C., Gold, L., \& Terrace, H. S. (1977). Trial and intertrial durations in autoshaping. Journal of Experimental Psychology: Animal Behavior Processes, 3, 264-284.

Grossen, N. E., \& Bolles, R. C. (1968). Effects of a classical conditioned "fear signal" and "safety signal" on nondiscriminated avoidance behavior. Psychonomic Science, 11, 321-322.

HAMmond, L. J. (1967). A traditional demonstration of the active properties of Pavlovian inhibition using differential CER. Psychonomic Science, 9, 65-66.

HAMMOND, L. J. (1968). Retardation of fear acquisition when the CS has previously been inhibitory. Journal of Comparative \& Physiological Psychology, 66, 756-759.

Hearst, E. (1978). Stimulus relationships and feature selection in learning and behavior. In S. Hulse, H. Fowler, \& W. K. Honig (Eds.), Cognitive processes in animal behavior (pp. 51-88). Hillsdale, NJ: Erlbaum.

Holland, P. C. (1977). Conditioned stimulus as a determinant of the form of the Pavlovian conditioned response. Journal of Experimental Psychology: Animal Behavior Processes, 3, 77-104.

Holland, P. C. (1983). Occasion-setting in Pavlovian feature positive discriminations. In M. L. Commons, R. J. Herrnstein, \& A. R. Wagner (Eds.), Quantitative analyses of behavior: Discrimination processes (Vol. 4, pp. 183-206). New York: Ballinger.

Holland, P. C. (1984). Differential effects of reinforcement of an inhibitory feature after serial and simultaneous feature negative training. Journal of Experimental Psychology: Animal Behavior Processes, 10, 461-475

Holland, P. C. (1985). The nature of conditioned inhibition in serial and simultaneous feature negative discriminations. In R. R. Miller \& N. S. Spear (Eds.), Information processing in animals: Conditioned inhibition (pp. 267-297). Hillsdale, NJ: Erlbaum.

Holland, P. C. (1986). Temporal determinants of occasion setting in feature-positive discriminations. Animal Learning \& Behavior, 14, 111-120.

Holland, P. C. (1989a). Acquisition and transfer of conditional discrimination performance. Journal of Experimental Psychology: Animal Behavior Processes, 15, 154-165.

Holland, P. C. (1989b). Feature extinction enhances transfer of occasion setting. Animal Learning \& Behavior, 17, 269-279.

Holland, P. C. (1989c). Transfer of negative occasion setting and conditioned inhibition across conditioned and unconditioned stimuli. Journal of Experimental Psychology: Animal Behavior Processes, 15, 311-328.

Holland, P. C. (1991). Transfer of control in ambiguous discriminations. Journal of Experimental Psychology: Animal Behavior Processes, 17, 231-248.

Holland, P. C. (1992). Occasion setting in Pavlovian conditioning. In D. L. Medin (Ed.), The psychology of learning and motivation (Vol. 28, pp. 69-125). New York: Academic Press.

Holland, P. C. (1995). The effects of intertrial and feature-target intervals on operant serial feature-positive discrimination learning. Animal Learning \& Behavior, 23, 411-428.

Holland, P. C. (1999). Intertrial interval effects in Pavlovian serial feature positive discriminations. Animal Learning \& Behavior, 27, 127-139.

Holland, P. C., \& Lamarre, J. (1984). Transfer of inhibition after serial and simultaneous feature negative discrimination training. Learning \& Motivation, 15, 219-243.

Holland, P. C., \& Reeve, C. E. (1991). Acquisition and transfer of control by an ambiguous cue. Animal Learning \& Behavior, 19, 113124.

Holland, P. C., \& Ross, R. T. (1981). Within-compound associations in serial compound conditioning. Journal of Experimental Psychology: Animal Behavior Processes, 7, 228-241.

Honey, R. C., \& WATt, A. (1998). Acquired relational equivalence: Implications for the nature of associative structures. Journal of Experimental Psychology: Animal Behavior Processes, 24, 325-334.

Honey, R. C., \& WATt, A. (1999). Acquired relational equivalence between contexts and features. Journal of Experimental Psychology: Animal Behavior Processes, 25, 324-333.

Kehoe, E. J., \& Gormezano, I. (1974). Effects of trials per session on conditioning of the rabbit's nictitating membrane response. Bulletin of the Psychonomic Society, 4, 434-436.

Lamarre, J., \& Holland, P. C. (1987). Acquisition and transfer of serial feature negative discriminations. Learning \& Motivation, 18, 319-342.

Looney, T. A., Cohen, L. R., Brady, J. H., \& Cohen, P. S. (1977). Conditional discrimination performance by pigeons on a responseindependent procedure. Journal of the Experimental Analysis of Behavior, 27, 363-370.

NAKAJIMA, S. (1998). Pavlovian feature-ambiguous discrimination. In N. A. Schmajuk \& P. C. Holland (Eds.), Occasion setting: Associative learning and cognition in animals (pp. 147-165). Washington, DC: American Psychological Association.

Pavlov, I. P. (1927). Conditioned reflexes (G.V. Anrep, Trans.). Oxford: Oxford University Press.

Pearce, J. M. (1987). A model for stimulus generalization in Pavlovian conditioning. Psychological Review, 94, 61-75.

Pearce, J. M. (1994). Similarity and discrimination: A selective review and a connectionist model. Psychological Review, 101, 587-607.

Perkins, A. S. (2002). Functional genomics in the mouse. Functional Integrative Genomics, 2, 81-91.

Picciotтo, M. R. (1999). Knock-out mouse models used to study neurobiological systems. Critical Reviews in Neurobiology, 13, 103-149.

Preston, G. C., Dickinson, A., \& Mackintosh, N. J. (1986). Contextual conditional discriminations. Quarterly Journal of Experimental Psychology, 38B, 217-237.

RESCORLA, R. A. (1985). Conditioned inhibition and facilitation. In R. R. Miller \& N. S. Spear (Eds.), Information processing in animals: Conditioned inhibition (pp. 327-353). Hillsdale, NJ: Erlbaum.

RESCORLA, R. A. (1986a). Extinction of facilitation. Journal of Experimental Psychology: Animal Behavior Processes, 12, 16-24.

RESCORLa, R. A. (1986b). Facilitation and excitation. Journal of Experimental Psychology: Animal Behavior Processes, 12, 325-332.

RESCORLa, R. A. (1987). Facilitation and inhibition. Journal of Experimental Psychology: Animal Behavior Processes, 13, 250-259.

Rescorla, R. A., \& Holland, P. C. (1977). Associations in Pavlovian conditioned inhibition. Learning \& Motivation, 8, 429-447.

Ross, R. T. (1983). Relationships between the determinants of performance in serial feature positive discriminations. Journal of Experimental Psychology: Animal Behavior Processes, 9, 349-373.

Ross, R. T., \& Holland, P. C. (1981). Conditioning of simultaneous and serial feature-positive discriminations. Animal Learning \& Behavior, 9, 293-303

SAAVEDRA, M. A. (1975). Pavlovian compound conditioning in the rabbit. Learning \& Motivation, 6, 314-326.

Schubert, M., Lachnit, H., Francucci, S., \& Giurfa, M. (2002). Nonelemental visual learning in honeybees. Animal Behaviour, 64, $175-184$.

Swartzentruber, D. (1998). Perspectives on modulation: Modulatorand target-focused views. In N. A. Schmajuk \& P. C. Holland (Eds.), Occasion setting: Associative learning and cognition in animals (pp. 167197). Washington, DC: American Psychological Association.

Tecott, L. H. (2003). The genes and brains of mice and men. American Journal of Psychiatry, 160, 646-656. 
Thomas, D. R., \& Goldberg, H. (1985). Conditional discrimination learning by pigeons: The role of training paradigms. Bulletin of the Psychonomic Society, 23, 256-258.

TraPOLD, M. A. (1970). Are expectancies based upon different positive reinforcing events discriminably different? Learning \& Motivation, 1, 129-140.

UrCUioli, P. J. (1984). Overshadowing in matching-to-sample: Reduction in sample-stimulus control by differential sample behaviors. Animal Learning \& Behavior, 12, 256-264.

UrCuioli, P. J. (1985). On the role of differential sample behaviors in matching-to-sample. Journal of Experimental Psychology: Animal Behavior Processes, 11, 502-519.

UrCUioli, P. J. (1990). Some relationships between outcome expectancies and sample stimuli in pigeons' delayed matching. Animal Learning \& Behavior, 18, 302-314.

WAGNER, A. R., \& BRANDON, S. E. (1989). Evolution of a structured con- nectionist model of Pavlovian conditioning (AESOP). In S. B. Klein \& R. R. Mowrer (Eds.), Contemporary learning theories: Pavlovian conditioning and the status of traditional learning theory (pp. 149189). Hillsdale, NJ: Erlbaum.

Wehner, J. M., Radcliffe, R. A., \& Bowers, B. J. (2001). Quantitative genetics and mouse behavior. Annual Review of Neuroscience, 24, 845-867.

Witcher, E. S., \& Ayres, J. J. B. (1984). A test of two methods for extinguishing Pavlovian conditioned inhibition. Animal Learning \& Behavior, 12, 149-156.

Zimmer-Hart, C. L., \& Rescorla, R. A. (1974). Extinction of Pavlovian conditioned inhibition. Journal of Comparative \& Physiological Psychology, 86, 837-845.

(Manuscript received August 22, 2003; revision accepted for publication January 17, 2005.) 